\title{
Using crocodilian tails as models for dinosaur tails
}

Heinrich Mallison, Michael Pittman, Daniela Schwarz

The tails of extant crocodilians are anatomically the closest approximation of the tails of non-avian dinosaurs, and therefore a good starting point for any reconstruction of nonavian dinosaur tail muscles. However, we here demonstrate some methodological problems using crocodile tails, firstly regarding the general reconstruction of tail mobility from osteology, secondly for the reconstruction of tail musculature for the quantification of muscle forces, especially the $\mathrm{m}$. caudofemoralis longus, and thirdly with respect to the anatomical differences between crocodilians and non-avian dinosaurs, especially in relation to the reconstruction of $\mathrm{m}$. caudofemoralis brevis. Our results show that, given the current limited knowledge of crocodilian tails, volumetric reconstructions should be created on the basis of more gross morphological data than is usually used, and that biomechanical studies should include sensitivity analysis with greater parameter ranges than often applied. 


\title{
Using crocodilian tails as models for dinosaur tails
}

\author{
Heinrich Mallison ${ }^{1, *}$, Michael Pittman $^{2} \&$ Daniela Schwarz ${ }^{1}$ \\ ${ }^{1}$ Museum für Naturkunde - Leibniz Institute for Evolution and Biodiversity Science, Invalidenstrasse \\ 43, 10115 Berlin, Germany. \\ ${ }^{2}$ Vertebrate Palaeontology Laboratory, Life and Planetary Evolution Research Group, Department of \\ Earth Sciences, The University of Hong Kong, Pokfulam, Hong Kong, China. \\ *Corresponding author: heinrich.mallison@mfn-berlin.de
}

\begin{abstract}
The tails of extant crocodilians are anatomically the closest approximation of the tails of non-avian dinosaurs, and therefore a good starting point for any reconstruction of non-avian dinosaur tail muscles. However, we here demonstrate some methodological problems using crocodile tails, firstly regarding the general reconstruction of tail mobility from osteology, secondly for the reconstruction of tail musculature for the quantification of muscle forces, especially the m. caudofemoralis longus, and thirdly with respect to the anatomical differences between crocodilians and non-avian dinosaurs, especially in relation to the reconstruction of $\mathrm{m}$. caudofemoralis brevis.

Our results show that, given the current limited knowledge of crocodilian tails, volumetric reconstructions should be created on the basis of more gross morphological data than is usually used, and that biomechanical studies should include sensitivity analysis with greater parameter ranges than often applied.
\end{abstract}

\section{Introduction}

Reconstructions of the life appearance and biomechanics of an extinct animal should always be based on the best available data. Because we typically lack solid information on the vast majority of soft tissues, the best data we can obtain usually stems from extant animals, both those taxonomically close and those biomechanically similar, the later criterion usually determined by a high degree of similarity in osteology. When reconstructing the tails of non-avian dinosaurs we must therefore turn to extant dinosaurs - but they all belong to a highly derived and aberrant group of theropods, with tails that have been much shortened, the vertebrae reduced in number and the vestiges of others coossified, and the whole structure co-opted for novel functions for flight and display. Therefore, bird tails are not good models for typical dinosaur tails, and a classic Extant Phylogenetic Braketing approach is not useful. In contrast, crocodylians possess long tails that are morphologically very similar to basal dinosaur tails, despite the greater taxonomic separation. Still, as archosaurian reptiles like dinosaurs, the tails of crocodilians can be used to reconstruct soft-tissue anatomy and overall mobility. The only other exant reptile group with long tails, Lepidosauria, is both phylogenetically and osteologically much more distant to archosaurs and can only partly contribute to our understanding of tail form and function.

Peerj PrePrints | https://dx.doi.org/10.7287/peerj.preprints.1339v1 | CC-BY 4.0 Open Access | rec: 2 Sep 2015, publ: 2 Sep 2015 
Many previous reconstructions of the soft-tissue anatomy of non-avian dinosaur tails have been created using extant crocodylians as analogon (e.g. Madsen, 1976; Carpenter et al., 2005; Persons, 2009; Mallison, 2010a; Persons \& Currie, 2011; Persons, Currie \& Norell, 2014). However, as we want to demonstrate in this paper, a number of missing data, interspecific variation within Crocodylia, and even false assumptions about crocodylian tails persist that lead to errors in non-avian dinosaur tail reconstructions. Two key claims made in the literature, the reconstruction of the lateral range of motion and the proper reconstruction of the extent of $\mathrm{m}$. caudofemoralis longus, will be discussed here by treating them as specific hypotheses and using both data from the literature and direct observations on crocodiles to test them. Additionally, we give a short summary of the axial tail musculature of extant crocodylians to show their form and spatial relationships along the tail, and discuss it in the context of previous uses for reconstructions in dinosaurs.

\section{Reconstructing the range of motion from the zygapophyseal articulations}

A key aspect in the reconstruction of non-avian dinosaurs is the assessment of the range of motion for different regions of the vertebral column. Mobility of the vertebral column in three dimensions is usually defined as lateral flexion, (ventral) flexion and (dorsal) extension. Long axis rotation or torsion (equivalent to the jaw, pitch, and roll terms used in aviation) may occur, but as shown for sauropod dinosaurs, is successfully limited by the zygapophyses (Schwarz-Wings et al., 2010). The range of motion in the neck of sauropod dinosaurs have been studied for years by a variety of researchers, using 2D and 3D models (Stevens \& Parrish, 1999, 2005a,b), and in comparison to extant animals (e.g. Taylor, Wedel \& Naish, 2009). Studies that give sophisticated and detailed comparisons with extant birds (Dzemski \& Christian, 2007; Cobley, Rayfield \& Barrett, 2013) have convincingly demonstrated that it is nearly impossible to deduce overall neck flexibility from the zygapophyseal articulations alone. In particular the embedding of the zygapophysis into an articular capsule significantly changes their contact behavior (Dzemski \& Christian, 2007; Taylor, Wedel \& Naish, 2009). Studies on the reconstruction of the flexibility of the axial skeleton of fossil crocodyliforms have shown that the overall mobility of regions of the vertebral column are the result of many different factors taken together: osteology of zygapophyses, neural spines, and osteoderms works in concert with ligaments, musculature and dermis, and in the end, only a comprehensive approach taking all of these factors into account, allows an estimation of overall flexibility (Salisbury, 2001; Salisbury \& Frey, 2001; Schwarz, Frey \& Meyer, 2007; Schwarz, Wings \& Meyer, 2007).

Although this has never be tested, it is self-evident to assume that the same mechanism which holds for the neck and trunk also holds for the tail, so caution should be taken in considering the results of studies relying on single parts of the anatomy of a certain body region.

With respect to lateral range of motion, it has been repeatedly claimed that steeply inclined zygapophyseal articulations hinder lateral mobility (Hypothesis 1). For example, regarding the vertebral column of the sauropodomorph dinosaur Massospondylus Cooper (1981, p. 720) stated:

Since the pre-and postzygapophyses of the cervical vertebrae [of Massospondylus] articulate at an angle of approximately $45^{\circ}$ to the horizontal, there was only limited lateral flexibility to the neck in life [...] Similarly, the presence of subvertical articular facets to the zygapophyses of the caudal series indicates that, perhaps but for the distal extremity, there was little lateral flexibility to the tail.

Barrett and Upchurch (2007) disagreed with Cooper's conclusions, not because they doubted that such an arrangement of the zvganonhvses would block lateral flexion hut hecause thev found the Peerj PrePrints | https://dx.doi.org/10.7287/peérj.preprints.1339v1 | CC-BY 4.0 Open Access | rec: 2 Sep 2015, publ: 2 Sep 2015 
zygapophyses to be arranged at a much shallower angle along most of the neck than stated by Cooper (1981). They stated (Barrett \& Upchurch, 2007, p. 98):

Such an arrangement [as described by Cooper (1981)] would indeed place severe limits on neck flexibility, effectively preventing mediolateral rotation around the intervertebral articulations as it would have been impossible for the pre-and postzygapophyses to slide past each other to a significant degree.

Similarly, regarding tail mobility in the ceratopsian dinosaur Psittacosaurus Sereno (1987, p. 186) stated:

Beyond the anteriormost caudals, the angle of the zygapophysial articulation is essentially vertical, restricting the lateral motion of the tail [...].

Penkalski described the zygapophyseal articulations near the end of the tail of Tarchia gigantea, an ankylosaurid dinosaur as "strongly inclined", and concluded that this orientation "would have severely limited lateral movement of the middle part of the tail“ (Penkalski, 2001, p. 281).

Interestingly, in crocodylians and varanids, which possess tails with great lateral mobility, the zygapophyseal articulations are angled steeply, at around $45^{\circ}$ or less from the vertical (Mallison, 2010a, and see below). Digital 3D manipulation of high-quality models of non-avian dinosaur vertebrae with steeply inclined zygapophyses indicates great lateral mobility as well (e.g. Mallison, 2010a,b). Additionally, some non-avian dinosaur fossils found articulated show strong lateral flexion of the tail without apparent disarticulation, despite steeply angled zygapophyseal surfaces (e.g. Ford \& Martin, 2010 for Psittacosaurus).

The only detailed work about the osteology-constrained tail flexibility in extant crocodylians is found in Virchow (1914). However, there are a number of accounts on the overall flexibility of the crocodylian tail. A detailed study of the "death roll" of the American alligator (Fish et al., 2007) gave angles for lateral flexion between body and tail, but it is unclear how the long axis of the tail was determined, as the position the animals were in included continuous flexion of the tail, not just at the base. A number of studies have described whole tail movements of crocodylians during swimming (Manter, 1940; Kälin \& Knüsel, 1944; Fish, 1984; Davenport \& Sayer, 1989; Frey \& Salisbury, 2001; Seebacher, Elsworth \& Franklin, 2003; Ringma \& Salisbury, 2013). A freshly killed American alligator's tail mobility was assessed by Frey (1982a), who had a helper move the tail into a maximally deflected position for lateral flexion, extension and flexion, and torsion each, then drew the body outline on cardboard. Salisbury \& Frey (2001) give a very detailed account on the overall tail flexibility of freshly dead or anaesthetized crocodilians.

An approach to determine the osteological range of motion of extinct animals is offered by articulated fossils, which can be analyzed graphically in 2D or, as laser scans or photogrammetric models, in 3D. This approach runs both the risk of assuming vertebrae to be articulated that were disarticulated after death, and the risk of accidentally interpreting a three-axis motion as one-axis motion, e.g. if long-axis rotation brings the lateral flexion axis of one joint into the same plane as the next joint's extension axis. However, there are many fossils that are preserved with their clearly still articulated tails extended into what is often termed opisthotonus pose (Faux \& Padian, 2007), so that measurements of deflection per joint are possible. For example, tails of Kentrosaurus aethiopicus 
were found "in a semicircle" (Hennig, 1913, 1925), so that digital 3D scans of the caudal vertebrae could be posed accordingly and the required per-joint deflection measured (Mallison, 2010a).

We use ex vivo range of motion experiments on a crocodile, skeletal measurements of zygapophyseal inclinations in several crocodiles, in combination with the above data on extant and extinct archosaurs from the literature to assess the validity of Hypothesis 1 and investigate dorsal and ventral range of motion of crocodile tails.

\section{Reconstructing tail muscles of non-avian dinosaurs based on crocodylian tail muscles}

The muscular anatomy of the crocodylian pelvis and tail has been investigated in detail by many scientists (e.g. Hair, 1868a; Romer, 1923a; Frey, 1982a,b, 1988; Frey, Riess \& Tarsitano, 1989; Cong et al., 1998; Hutchinson \& Gatesy, 2000; Wilhite, 2003; Allen, Paxton \& Hutchinson, 2009; Persons, 2009; Allen et al., 2014). We supplemented these studies with own data and data provided by third parties (see below) and note where previous works differ in their findings between and within various taxa. Note that it is not our aim to quantify ontogenetic, sexual and individual variation in the muscular anatomy of modern crocodylians. Rather, we focus selectively on those aspects important for the reconstruction of non-avian dinosaur tails.

Generally, how far the muscles of the tail extend ventrally, laterally and dorsally beyond the bone is a matter of contention. Allen et al. (2009), Persons (2009), Persons and Currie (2011), Mallison (2011) and others have shown that the soft tissues in the tails of crocodiles and many squamates extend significantly beyond the bones dorsally and especially ventrally and laterally (Error! Reference source not found.), whereas other studies have used the extent of the bones as the extremes of soft tissue reconstructions (Carpenter et al., 2005).

Among axial tail muscles, the extent/expansion of $\mathrm{m}$. caudofemoralis longus, both in length and especially in lateral and ventral directions, was always of special interest. This is probably due to its important role as a limb retractor in archosaurs. In particular, the attachment of $\mathrm{m}$. caudofemoralis longus both on the femur and caudal vertebral column makes it necessary, that during contraction of the muscle, either the femur is moved and the tail stabilized, or vice verca. Lateral motion of the tail is achieved by synchronous or ipsilateral contraction of the epaxial musculature and/or m. ilio-ischio-caudalis. Naturally, the femur cannot be stabilized during terrestrial locomotion, which defines caudofemoralis longus as being used for femoral and limb retraction and simultaneously stabilized the tail during terrestrial locomotion. It can be assumed that this mechanism is applicable both to crocodylians and non-avian dinosaurs. Relationships would be different during aquatic locomotion, but this does not apply to non-avian dinosaurs, at least for time being. Summing up, $\mathrm{m}$. caudofemoralis longus is, because of its role as a femoral retractor, is most important for biomechanical analyses and therefore, its origins, attachments and size should be reconstructed with as much precision as possible. Unfortunately, whereas the medial and dorsal borders of $\mathrm{m}$. caudofemoralis longus are defined by bone, and whereas the ventral extent for most of its length is also defined by bony correlates, the lateral border cannot be determined from bones, and must therefore be reconstructed in extinct taxa. Persons (2009) developed a method for reconstructing the full extent of $\mathrm{m}$. caudofemoralis longus by approximating the lateral border of this muscle by a semicircle between bony landmarks, an important step forward for volumetric tail 
muscle modelling. As the absolute size/cross-section of $\mathrm{m}$. caudofemoralis is the basis for many reconstructions of muscles forces and hind-limb movement, we test Persons' (2009)

$\mathbf{m}$. caudofemoralis longus reconstruction method as Hypothesis $\mathbf{2}$, and we also discuss under this hypothesis the value of other crocodylian axial tail muscles for reconstructing non-avian dinosaur tails.

\section{Institutional abbreviations}

AMNH - American Museum of Natural History, New York, USA

AUCVM - Auburn University College of Veterinary Medicine, Auburn, USA

GPIT - collection numbers of IFGT

HU Zool.Coll. - Zoological Teaching Collection, Humboldt Universität zu Berlin, Germany

IFGT - Palaeontology Department and Museum, Institut of Geosciences, Eberhard Karls University

Tübingen, Germany

IPFUB - specimens previously from Free University Berlin now curated at MfN

IVPP - Institute of Vertebrate Paleontology \& Paleoanthropology, Beijing, China

MfN - Museum für Naturkunde - Leibniz Institute for Evolution and Biodiversity Research, Berlin, Germany

MPC - Mongolian Paleontological Center, Mongolian Academy of Sciences, Ulaan Bataar, Mongolia

RVC - Royal Veterinary College, UK

STM - Shandong Tianyu Museum of Natural History, Pingyi, Shangdong, China

UNE - University of New England, Armidale, Australia

$\mathrm{ZMB}$ - Zoological collection of MfN

\section{Materials and Methods}

\section{Muscle anatomy data}

We collected data on the tail musculature of extant crocodylians from the literature (see above), from our own dissections of crocodylians, from CT and MRI scans provided by A. Klinkhammer and S. Wroe (both UNE) of a large (>2 $\mathrm{m}$ snout to tail tip) individual of Crocodylus porosus, and from dissection photographs provided by R. Wilhite (AUCVM). Additionally, we used photographs of a series of transverse sections of a $\sim 1 \mathrm{~m}$ Alligator mississippiensis provided by D. Hillmann and R. Wilhite (AUCVM). Four examples and interpretative drawings are shown in Error! Reference source not found.. These photographed tail slices were also used to test Persons' (2009) reconstruction method for $\mathrm{m}$. caudofemoralis longus (Hypothesis 2), by tracing the muscle on selected slices and creating an approximation using Persons' method. We could not determine exactly if Persons' (2009) method uses a semicircle or just part of one, i.e. if the arc Persons uses dorsally ends at contact with the vertebral centrum or continues to the vertical. Therefore, we tested both versions.

\section{Ex vivo and digital range of motion measurements and analyses}

An ontogenetically young specimen of Osteolaemus tetraspis with a total length of $110 \mathrm{~cm}$ was provided by J.R. Hutchinson (RVC) for tail range of motion experiments. Freshly killed specimens are preferred for such experiments, but logistical constraints meant we could only use a frozen one, which we thawed for $\sim 24$ hours prior to our experiments. For cadaveric human spine specimens, range of motion appears to be unaffected if tested after episode of freezing (Panjabi, Summers \& Videman, 1985). In contrast, range of motion decreases after one freezing episode for cadaveric pig Peer] PrePrints | https://dx.doi.org/10.7287/peerj.preprints.1339v1 | CC-BY 4.0 Open Access | rec: 2 Sep 2015, publ: 2 Sep 2015 
spine specimens, but then remains relatively unchanged after subsequent freezings (Hongo et al., 2008). It is unclear which of these scenarios our specimen fits into - and this obviously deserves further investigation - but the wide acceptance of frozen cadavers specimens in biomechanics research helps to support of sampling method and actually allow a direct comparisons with many existing studies. The specimen was CT scanned at the Royal Veterinary College's CT facility using a GE LightSpeed VCT scanner in four positions: straight, maximum tail extension and maximum tail flexion, as well as maximum lateral flexion of the anterior half of the tail. Slice thickness was $0.25 \mathrm{~mm}$. During manipulation of the specimen we noted a slight inequality in lateral spine mobility probably related to the laterally contorted position the specimen was frozen in. Therefore, the lateral motion range experiment was conducted with the specimen bent in the same direction it had been stored in. It is unclear how much influence subjecting the specimen to multiple freezing cycles in a strongly flexed pose have on the results of our experiments as this is not specifically discussed in the literature. Therefore, we wanted to test lateral flexion on the other side too. However, we found that the manipulation we performed had begun to damage some joints, breaking the joint capsules. Further manipulation would therefore have led to definitively unrealistic results so the second lateral bending test was aborted.

We used two sheets of perforated hardboard held ca. $20 \mathrm{~mm}$ apart by threaded nylon spacers as a base, on which we could securely fix the specimen in any pose by inserting thin wooden dowels (diameter ca. $2 \mathrm{~mm}$ ) into the perforations of both sheets of the base where required. The specimen was manipulated into maximum deflection. We deflected the entire tail with as little motion around any other axis as possible, and then placed the specimen on the wooden board in this position. Then we fixed the specimen first at the hip, then progressively down the tail, while continuously bending the specimen into maximum deflection. Due to the incremental fixation we can be sure to have maximized joint motions locally all along the tail, instead of just overall. The sole exception was the lateral bending tail, which we limited to the anterior half of the tail as described below.

The CT scans of Osteolaemus tetraspis were analyzed for range of motion by extracting the bone via threshold labelling in ZIB-AMIRA 2014.41 and exporting them as StereoLithography polymesh files (STL). Clean-up including removal of osteoderms and smoothing were undertaken in Geomagic 8.0. The files were then imported into Rhinoceros 5.0 and aligned with the craniocaudal axis of the pelvis parallel to a main program axis (in dorsal view of extension and flexion, and in lateral view for the laterally flexed tail). For the flexed and extended tail a clipping plane was created and shifted so that it ran through the neural canals. Then, lines were placed along the ventral surfaces of the neural canals. The angles between consecutive vertebrae were measured by using the 'angle' command in lateral view. This measures the angles as projected to the construction plane of the viewport, which means that any unintended deflection in any other direction leads to small discrepancies between the angles reported here and the actual angles. We tested the error by introducing a new construction plane and rotating it to match the actual neural canal long axis for several vertebra pairs, projecting the angle onto it and measuring there. However, the discrepancies were all below $2^{\circ}$, and the errors between repeated alignments of the construction plane were nearly as large. We therefore concluded that the gain in accuracy from using an optimized construction plane instead of the default position would be negligible, given the uncertainty necessarily inherent in the process of placing the lines that mark the long axes of the neural canals. Similarly, the angles of the lateral flexion experiment were measured in dorsal view, although the tail was slightly flexed ventrally. In any case, the deviations between actual and measured angles are even less critical, as any error in 
one measurement gets compensated in the next. By calculating a running average across three joints the error becomes negligible.

Additionally, we used own photographs, in vivo photogrammetric 3D models and videos (youtube.com, search term "crocodile feeding") of living crocodylians to assess if the maximum deflection poses of the Osteolaemus specimen were matched by living crocodylians, or exceeded the positions seen in the videos.

For further validation we also extracted three vertebrae from the tail base of the CT scans of Crocodylus porosus provided by S. Wroe and A. Klinkhammer, and digitally manipulated them in Rhinoceros to determine the maximum deflections. For this we followed the protocol described by Mallison (2010b). Also, the skeletonized tail of Crocodylus niloticus (ZMB 82861, a 70 year old male the MfN obtained from the Zoologischer Garten Berlin in 2010, caudals 1 through 29) was physically manipulated by HM to further confirm our CT-based results.

\section{Zygapophyseal inclination measurements}

In one individual of Crocodylus porosus (caudal vertebrae 1 through 14, the rest of the tail is missing; IPFUB OS 13), one individual of $C$. niloticus (caudals 1 through 29, ZMB 82861), and one specimen of Alligator mississippiensis (caudal vertebrae 2 through 31; HU Zool.Coll. 1914 Nr. 81) the transverse inclinations of the zygapophyseal joint surfaces were measured on digital photographs of the prepared bones taken in anterior and posterior views, respectively, by importing the photographs into Rhinoceros 5.0, drawing a straight line along the zygapophyseal surface, and measuring with the angle command versus the vertical of the photograph. All contralateral value pairs were then averaged.

\section{Results}

\section{Hypothesis 1 - Range of motion and zygapophyseal articulation orientation}

Table 2 gives the measured deflections per intervertebral joint of the range of motion of the tail of Osteolaemus tetraspis measured ex vivo. Measurements of the inclination of pre- and postzygapophyseal surfaces from the vertical in extant crocodilians are given in Table 3.

Previously, Frey's (1982) crude but effective method of manually bending an alligator's tail and drawing the outline on cardboard showed a maximum lateral flexion of ca. $480^{\circ}$ for the entire tail, i.e. a full circle plus slightly more than a right angle, allowing it to be rolled up laterally (Salisbury \& Frey, 2001). Our ex vivo experiments on a young specimen of Osteolaemus tetraspis showed slightly less mobility in the horizontal plane than those of Frey (1982a), with the tail not having quite enough lateral mobility to be rolled up in a plane. Instead, the tail could be rolled up into a spiral only, i.e. with dorsoventral offset, although the overall angle was close to $440^{\circ}$. We therefore limited the test to maximum lateral flexion along the proximal half of the tail. It is unclear how freezing and thawing of the specimen and muscle tissue decay (visible in the CT scans as air pockets) influenced our results. Dorsal (ca. $130^{\circ}$ ) and ventral (ca. $145^{\circ}$ ) mobility were found to be much more restrained than lateral bending (Frey, 1982a), but are larger than the $100^{\circ}$ dorsally and $90^{\circ}$ ventrally described by Salisbury \& Frey (2001) for extant crocodylians.

Frey (1988) describes for Alligator mississippiensis that the articular surfaces of the zygapophyses are reduced distally, and that the degree of their inclination is $20^{\circ}$ to the horizontal PeerJ PrePrints | https://dx.doi.org/10.7287/peerj.preprints.1339v1 | CC-BY 4.0 Open Access | rec: 2 Sep 2015, publ: 2 Sep 2015 
plane at the $23^{\text {rd }}$ caudal vertebra. Further distally, the articular processes are reduced to small, rodlike processes that lack a distinct articular surface. This is also evident in other crocodylian species, such as Crocodylus niloticus, C. porosus, or Tomistoma schlegelii (DS pers. obs). The reduction of the zygapophyses in the caudal half of the tail means that they cannot limit tail mobility in this region at all, and indeed, flexibility of the tail including a certain amount of torsion increases in the terminal part of the crocodylian tail (Salisbury, 2001; Salisbury \& Frey, 2001, but see also Manter, 1940; and Davenport \& Sayer, 1989 for a description). This underscores the important role of the zygapophyses for torsion control, which might even dominate over the control of mobility of the vertebral column.

As our data show, the inclination of the zygapophyses as determined from photographs of Alligator mississippiensis (Table 3 ) becomes steeper distally, ranging from ca. $40^{\circ}$ from the horizontal plane at the tail base to ca. $78^{\circ}$ in the $24^{\text {th }}$ caudal. In Alligator mississippiensis the corresponding preand postzygapophyseal articulation surfaces are nearly parallel to each other throughout the proximal three fourths of the tail. Starting with caudal vertebra 24 , in the distal quarter of the tail the prezygapophyseal surfaces are suddenly much less steeply oriented, whereas the postzygapophyses remain steeply angled (PLEASE SEE SEPARATE FILE FOR Figure 2, Table 3). In Crocodylus porosus (proximal half of the tail) a similar trend is visible, but the angles are ca. $5^{\circ}$ steeper in the basal third of the tail, and subequal in the middle part. In C. niloticus

\section{Hypothesis 2 - Tail muscle reconstructions using extant crocodylians}

\section{Epaxial musculature of the tail}

The epaxial tail musculature of extant crocodylians consists, as in the trunk of a medial m. transversospinalis system, and a lateral m. longissimus caudae (Romer, 1923a; Frey, 1982a, 1988; Frey, Riess \& Tarsitano, 1989; Cong et al., 1998). Subdivisions of $\mathrm{m}$. transversospinalis are $\mathrm{m}$. multifidus, $\mathrm{m}$. spinalis (terminating variably at the $13^{\text {th }}$ or $14^{\text {th }}$ caudal vertebra), $\mathrm{m}$. articulospinalis, and as most lateral part of $\mathrm{m}$. transversospinalis, $\mathrm{m}$. tendinoarticularis caudae. The latter is only mildly developed in the tail base, which corresponds to an increase in cross section of $\mathrm{m}$. longissimus caudae. This relative thinning of parts of $\mathrm{m}$. transversospinalis compared to $\mathrm{m}$. longissimus caudae is not represented in previous muscle volume modeling attempts (Arbour, 2009; Persons, 2009; Persons \& Currie, 2011; Persons, Currie \& Norell, 2014), but given the lack of osteological correlates for the contact between the two muscles any reconstruction must remain speculative. Reference to the medial m. transversospinalis system as m. spinalis as in Carpenter et al. (2005) and Persons (2009) is misleading, because this is only a part of the whole muscle group, and does not correspond to homology hypotheses of the muscle group (see Tsuihiji, 2005).

$M$. longissimus caudae increases in diameter in the tail base, and its myoseptal cones turn more laterally than in the trunk. The muscle expands even into a second system of myosepts called $\mathrm{m}$. longissimus caudae pars A (Frey, 1988), which lies topographically beneath the main $\mathrm{m}$. longissimus caudal myosepts. Interestingly, m. longissimus caudae pars A appears in Alligator mississippiensis at the $11^{\text {th }}$ caudal vertebra, which is the first caudal vertebra without transverse process (Frey, 1988). The epaxial tail muscle systems are ventrally and medially constrained by the transverse processes and the septum transversum, and the centra and neural arches of the caudal vertebrae.

In Alligator mississippiensis, $\mathrm{m}$. transversospinalis and $\mathrm{m}$. longissimus caudae are separated by a septum that steeply extends dorsolaterally from the tips of the zygapophyses at the base of the tail. Distally, the origin of the septum shifts to a position about two-thirds up the neural spine (Error!

Reference source not found.). Near the tail tin $m$. transversospinalis svstem is restricted to a small Peerj PrePrints | https://dx.doi.org/10.7287/peerj.preprints.1339v1 | CC-BY 4.0 Open Áccess | rec: 2 Sep 2015, publ: 2 Sep 2015 
area around the tip of the neural spines, whereas $\mathrm{m}$. longissimus caudae is much more prominent. Subdermal fat depots can occur in the epaxial region (Error! Reference source not found.), but adipose tissue is more frequently found within the hypaxial musculature around tendons and myosepts (Frey, 1988).

\section{Hypaxial musculature of the tail}

\section{M. ilio-ischio-caudalis}

syn. ischio-coccygien (Cuvier, 1835), M. ischio-coccygeus (Gorski, 1852), M. ilio-ischiococcygeus (Hair, 1868b); Mm. ileococcygeus and ischiococcygeus (Stannius, 1854); M. ilioischio-caudalis (Gadow, 1882; Frey, 1982a)

M. ilio-ischio-caudalis is highly compartmentalized in crocodiles, but rarely described in detail. Frey (1982a) mentioned four portions in Paleosuchus trigonatus and Caiman crocodilus. A large dorsal part originates from the medial side of the postacetabular process of the ilium, from which a deep dorsal portion extends to the lateral surfaces of the centra of caudal vertebrae 3 and 4 and the ventral surfaces of the transverse processes (Frey, 1982a). Dorsally to it, a much smaller medial dorsal portion runs from the same origin to the corresponding areas of the first and second caudal vertebrae (Frey, 1982a). Our own data matches Frey's (1982a) description. The largest part of $\mathrm{m}$. ilioischio-caudalis forms the ventral body wall of the tail, originating from the medial side of the postacetabular process and from the distal tip of the ischium. The two heads meet at the level of the third caudal vertebra in Caiman crocodilus, Paleosuchus trigonatus and Alligator mississippiensis (Frey, 1982a, 1988; own data). Frey (1982a, 1988) gave a detailed description of the complicated internal anatomy of the main part, which is subdivided into longitudinal segments that are arranged in sagittal series extending alternatingly anteriorly and caudally. A fourth portion is here treated separately as m. transversus perinei (see below). Romer (1923a) did not mention the two dorsal portions, but described $m$. transversus perinei (see next section).

The mediolateral thickness of $\mathrm{m}$. ilio-ischo-caudalis is not tied to any osteological correlates in the tail, as its path extends fully outside the bone-touching muscles for most of the tail (Error! Reference source not found.). The only direct limit can be inferred from the transverse extent of the pelvis. However, as a dorsal view of any living crocodile shows, the tail bulges laterally, so that even pelvis width is not directly translatable into a geometric maximum limit of tail width and thus the extent of the individual muscles, but can only serve as a minimum limit. In some non-avian dinosaurs, the caudal end of the pelvis is much wider in proportion than in crocodilians. In such cases the pelvis width should be cautiously used to delimit the lateral extent of $\mathrm{m}$. ilio-ischio-caudalis, but some lateral bulging of the muscle directly posterior of the pelvis cannot be excluded.

\section{M. transversus perinei (Romer 1923)}

syn. M. transversus caudae (Frey, 1988)

This muscle was regarded as a separate portion of m. ilio-ischio-caudalis by both Romer (1923a) and Frey (1982a, 1988; Frey, Riess \& Tarsitano, 1989). Cong et al (1998) regard both $m$. transversus perinei and $\mathrm{m}$. sphincter cloacae as separate entities derived from $\mathrm{mm}$. subvertebrales. Although the homology between $\mathrm{mm}$. subvertebrales and $\mathrm{m}$. transversus perinei is not to be cleared by us, we follow the treatment of $\mathrm{m}$. transversus perinei as a separate muscle, because of the marked difference of fiber direction between all portions of $\mathrm{m}$. ilio-ischio-caudalis on one hand and $\mathrm{m}$. transversus perinei on the other hand. Its fibers run in the transverse plane at nearly a right angle 
to $\mathrm{m}$. ilio-ischiocaudalis, encircling $\mathrm{m}$. caudofemoralis longus at the base of the tail (Figure 1). Whereas Romer (1923a) briefly mentioned $\mathrm{m}$. transversus perinei (as a part of $\mathrm{m}$. ilio-ischiocaudalis), and both Cong et al. and Frey discussed both the origins, belly architecture and insertion in detail (Frey, 1982a; Cong et al., 1998), many other studies including descriptions of extant crocodilian musculature and reconstructions of those of extinct archosaurs have overlooked it, whether they concern limb muscles, tail muscles, or both (e.g. Romer, 1923b, 1927; Huene, 1926; Madsen, 1976; Norman, 1986; Dilkes, 2000; Carrano \& Hutchinson, 2003; Hutchinson, 2004a,b; Hutchinson et al., 2005; Fechner, 2009; Bates et al., 2012; Maidment et al., 2013; Allen et al., 2014).

According to Frey (1982a) m. transversus perinei originates, via a strong tendon, on the medial side of the anterior rim of the ischium in both Paleosuchus and Caiman. It runs transversely around the tail base, inserts into the ventrolateral surfaces of the centra of caudal vertebrae 1 and 2 , and is isolated completely from the anterior m. ilio-ischio-caudalis by a fascia (Frey, 1982a). It comes to the surface of the tail in the triangle formed by the posterior edge of the thigh and the two heads of the main portion of m. ilio-ischio-caudalis (Frey, 1982a). Cong et al. (1998) mentioned that in Alligator sinensis the muscle is split into a dorsal and a ventral venter, connected by an aponeurosis that is narrower than the muscle bellies. According to Cong et al. (1998) the dorsal venter originates from the centra of caudal vertebrae 1 through 4 , and the ventral venter splits into two portions, the anterior of which insert on the posterolateral corner of the ischium and the posterior of which inserts, through an aponeurosis, on the cloacal cartilage. Both the physical cross sections and dissections of Alligator mississippiensis and the MRI scans of Crocodylus porosus confirm the descriptions by Frey (1982a) and Cong et al. (1998) in general terms. Contra Romer (1923a) the ventral venter inserts on the cloacal cartilage as described by Cong et al. (1998), not on the sphincter cloacae (Error! Reference source not found.).

Although $\mathrm{m}$. transversus perinei is small, at $1.5 \%$ of the total tail muscle volume, it plays an important role in shaping the external form of the tail base by wrapping $\mathrm{m}$. caudofemoralis longus. This effect is well visible in the cross sections of Alligator mississippiensis, which show an overall cross section reminiscent of a rounded rectangle in the region of $m$. transversus perinei, but a noticeable lateral bulging of the lateral body wall below the level of the transverse processes immediately posterior (Error! Reference source not found.).

\section{M. caudofemoralis brevis}

syn: M. obturator internus (Buttmann, 1826), M. pyriformis (Stannius, 1854), Auswärtsroller des Oberschenkels ("outward roller of the thigh", partim, Gorski, 1852), M. quadratus femoralis (Alligator, Haughton, 1865), M. obturator externus (Crocodylus, Haughton, 1865), M. pyriformis, M. glutaeus minor (Hair, 1868a), M. caudifemoralis (partim, Gadow, 1891), M. coccygeo-femoralis brevis (Romer, 1923a), M. caudifemoralis brevis (Frey, 1982).

M. caudofemoralis brevis is a broad muscle that connects the femur with the caudal part of the ilium and the anteriormost transverse processes (Figure 3 ). Its origin lies directly caudally to $\mathrm{m}$.

caudofemoralis longus and is an oblique, oval-shaped and broad aponeurosis situated in the proximal third of the ventral face of the femur caudal and dorsal to the $4^{\text {th }}$ trochanter. Viewed from internally (the side turned to the femur), the tendon of the origin of $\mathrm{m}$. caudofemoralis brevis expands from its insertion at the femur in the direction of the ilium and forms a layer that covers a third of the total internal surface of $\mathrm{m}$. caudofemoralis brevis. The muscle belly extends along the femur and covers the $\mathrm{m}$. ischiotrochantericus (Figure 3 ). The lateral third of the muscle inserts with muscle fibers in a 
broad area at the caudoventral margin of the ilium, whereas the medial two thirds extend further medially to insert ventrally at the vertebral centra of the second sacral and first caudal, as well as ventrally on the transverse processes. Caudally, the muscle is in contact with $\mathrm{m}$. ilio-ischio-caudalis, whereas ventromedially, it overlies the much larger m. caudofemoralis longus and excludes it from a contact to the transverse processes (Carrano \& Hutchinson, 2002; Frey, 1988; Romer, 1923; Wilhite, 2003). Unique among extant crocodylians, m. caudofemoralis brevis is absent in extant Gavialis gangeticus (Frey, 1982a,b, 1988; Frey, Riess \& Tarsitano, 1989). More inclusively amongst extant reptiles, Persons \& Currie (2011) state that the m. caudofemoralis brevis originates from the brevis fossa on the ilium and potentially across the anteriormost caudal and the $\mathrm{m}$. caudofemoralis longus as well. Gatesy (1990) noted that the muscle originates from the ilium and anterior caudals in most saurians. However, extant crocodylians do not have a brevis fossa on their ilia and are therefore of limited use for the reconstruction of $\mathrm{m}$. caudofemoralis brevis in non-avian dinosaurs. Thus, the latter must be reconstructed with caution.

\section{M. caudofemoralis longus}

syn: M. pyriformis (Buttmann, 1826), m. subcaudalis (Stannius 1854), m. femoro-peroneococcygien (Cuvier, 1835; Gorski, 1852); m. externus femoris caudalis (Haughton, 1865); m. femoroperineo-coccygeus (Hair, 1868); m. caudofemoralis (partim) (Gadow, 1882); m. coccygeofemoralis longus (Romer, 1923), Mm. coccygeofemorales (Cong et al., 1998)

The largest individual muscle in the archosaurian tail is the $\mathrm{m}$. caudofemoralis longus. It serves as the main retractor of the limb, but also adducts and longitudinally rotates the femur (e.g. Gatesy, 1990). The muscle extends caudally from the tail base and is roofed by the transverse processes of the caudal vertebrae. Its cross-section decreases along its length until the muscle terminates at around the $14^{\text {th }}$ caudal vertebra. The origin of $\mathrm{m}$. caudofemoralis lies on the cranioventral face of the femur at the $4^{\text {th }}$ trochanter.

A deep cleavage divides $\mathrm{m}$. caudofemoralis longus at its origin into a part associated with the femur, and another part that forms a long, rounded and thick tendon extending on the femur distally. This second, large tendon inserts laterally at the fibular head (Figure 3). Shortly before its insertion, $m$. gastrocnemius branches off from the massive tendon at the caudolateral side of the distal femur, so that $\mathrm{m}$. caudofemoralis longus is in direct contact with this largest muscle of the lower leg (Figure 3 ). There is general agreement on the attachments of $m$. caudofemoralis longus with a short tendon into the lateral surface of the $4^{\text {th }}$ trochanter of the femur (and into a shallow pit medial to the trochanter (Gatesy, 1990)), and with an accessory (auxiliary) tendon arising from the main tendon running down the limb (e.g., Romer, 1923a; Frey, 1982a, 1988; Frey, Riess \& Tarsitano, 1989; Gatesy, 1990; Hutchinson, 2001; Wilhite, 2003; Persons, 2009). Cong et al. (1998) only mention a connection to the M. gastrocnemius in the Alligator sinensis, but do not describe the exact origin of the tendon. Ibiricu et al. (2014) did not mention the accessory tendon in their summary of published crocodylian m. caudofemoralis descriptions at all. Persons \& Currie (2011) mentioned a connection "to the knee joint" in extant reptiles, but did not give any further details. Romer (1923a) mentioned that the tendon inserts ventrally onto the fibula. Allen et al. (2014) did not describe the muscle, but show the accessory tendon originating from the proximal tendon of the $\mathrm{M}$. gastrocnemius externus in a scheme of the generalized musculature of crocodylians. Gatesy (1990) noted that the accessory tendon attaches by an array of tendinous connections to the knee and the musculature of the lower leg. The most detailed description can be found in Frey (1982a), who noted that the tendon splits into two parts, one inserting into the top of the M. gastrocnemius, the other into the medial aspect Peer] PrePrints | https://dx.doi.org/10.7287/peerj.preprints.1339v1 | CC-BY 4.0 Open Access | rec: 2 Sep 2015, publ: 2 Sep 2015 
of the medial condyle of the femur in both Paleosuchus trigonatus and Caiman crocodylus. Allen (2010) gave a similar description for the generalized body plan of extant crocodilians.

M. caudofemoralis longus unites into one big muscle belly level with the proximal femoral articular surface. It is tightly bound within $\mathrm{m}$. ilioischiocaudalis. From its origin, the muscle extends straight medially and then curves caudally to parallel the caudal vertebrae. The cranialmost muscle fibers insert at the lateral surface of the $2^{\text {nd }}$ caudal vertebral centrum, and there and further posteriorly insert ventrolaterally at the vertebral centra, laterally on the haemapophyses and the bounding septum between adjacent haemapophyses. In some individuals, the muscle sometimes does not insert on the caudal centrum at all after the first few caudals. There is no direct contact of muscle fibers to the transverse processes of the tail and to the surrounding $\mathrm{m}$. ilioischiocaudalis, from which the muscle is isolated by a layer of connective tissue and small adipose bodies.

M. caudofemoralis longus usually ends on those vertebrae associated with the first segment of the tail region with a single medial keeled osteoderm. The caudal extent of $\mathrm{m}$. caudofemoralis longus is somehow related to the transverse processes in crocodylians, but there is some controversy on this topic in the literature (see Ibiricu, Lamanna \& Lacovara, 2014). As described by Persons \& Currie (2011) and previously by others, m. caudofemoralis longus in extant reptiles tapers in dorsoventral extent distally, while an increasing amount of the lateral face of the haemapophyses comes in contact with $\mathrm{m}$. ilio-ischio-caudalis. In some cases, there is a scar visible on the lateral faces of the haemapophyses that likely represents the septum separating the tapering $\mathrm{m}$. caudofemoralis longus from m. ilio-ischio-caudalis (Persons \& Currie, 2011). The distal end of m. caudofemoralis longus may also be determined by the absence of a transverse process (Persons \& Currie, 2011). However, the same authors found that the processes, which also serve as attachment areas for $\mathrm{m}$. longissimus caudae and the main portion of $\mathrm{m}$. ilio-ischio-caudalis, exist beyond the caudal terminating point of $\mathrm{m}$. caudofemoralis longus in some squamates. Cong et al. (1998) mentioned that after the $17^{\text {th }}$ caudal vertebra the transverse processes disappear completely in Alligator sinensis, but made no note in their English summary whether this point coincides with the termination of $\mathrm{m}$. caudofemoralis longus. The physical tomographies of Alligator mississippiensis clearly show well-discernible transverse processes in the distal tail, several slices and therefore at least two vertebrae past the distal tip of m. caudofemoralis longus. In Crocodylus niloticus (ZMB 82861) the transverse processes are visible as separate structures on caudals 1 through 11 . Caudal 12 has only a small, slightly raised rugosity, and from caudal 13 on there are no traces of transverse processes to be found. In Crocodylus porosus ("Stumpy") the transverse processes are much shorter than the lateral extent of $\mathrm{m}$. caudofemoralis longus at the base of the tail, but persist to caudal 15 as large processes. In caudals 16 and 17 only very small processes are visible. M. caudofemoralis longus begins to taper noticeably in the CT slices at around caudal 9, and terminates at caudal 13 (or possibly 14). Therefore, the transverse processes persist as large processes in at least three caudal vertebrae beyond the taper point, and are present, albeit proportionally to centrum size in much smaller form, in at least two caudal vertebrae beyond the termination point of $\mathrm{m}$. caudofemoralis longus. Interestingly, the haemapophyses between caudal vertebrae 17 and 18 is the first that deviates from the more anteriorly simple shape in that the distal tip has an anteroventral keel that points forward, so that in lateral view the tip forms a shallow triangle with its long side parallel to the horizontal.

Person's (2009) method for reconstructing $\mathrm{m}$. caudofemoralis longus in non-avian dinosaurs Persons (2009) correctly pointed out that the lateral width of the transverse processes is often a poor indicator of the lateral extent of $\mathrm{m}$. caudofemoralis longus across a wide range of reptiles. Our results PeerJ PrePrints | https://dx.doi.org/10.7287/peerj.preprints.1339v1 | CC-BY 4.0 Open Access | rec: 2 Sep 2015, publ: 2 Sep 2015 
for Alligator mississippiensis and Crocodylus porosus confirm this finding, as the transverse processes are narrower than the muscle at the tail base in the two individuals we studied, are wider than the muscle distal to the taper point, and even persist beyond the termination point.

Tests with the cross section photographs of Alligator mississippiensis show that the underestimation of the total volume of the M. caudofemoralis longus by Persons' method may be significantly larger than the $5 \%$ error noted by Persons (2009). The set of images we were provided with contains 32 photographic slices from the end of the pelvis to the caudal end of $\mathrm{m}$. caudofemoralis longus, with 26 of them caudal to the cloaca (i.e. in the tail region with haemapophyses). We tested slice numbers 7 , $9,13,17,21,25$ and 29 , i.e. the $1^{\text {st }}, 3^{\text {rd }}, 7^{\text {th }}, 11^{\text {th }}, 15^{\text {th }}, 19^{\text {th }}$ and $23^{\text {rd }}$ slices caudal of the cloaca (Figure 4). Beginning with post-pelvic slice No. 25 (the $19^{\text {th }}$ slice caudal of the cloaca) $\mathrm{m}$. caudofemoralis longus occupies only part of the lateral aspect of the haemapophyses, indicating that it is close to its caudal extreme. Anterior to this slice Persons' method consistently underestimates the cross section area of the M. caudofemoralis longus, on average by $38 \%$ versus the semicircle version of the Persons method and $45 \%$ versus the arc version, with the largest discrepancy of $57 \%$ (arc) and $52 \%$ (semicircle) at the first slice, and decreasing error values along the tail (Table 1). In the two posteriormost slices that were tested, where the $\mathrm{m}$. caudofemoralis longus has tapered almost fully, the Persons method substantially overestimates the cross sectional area, mostly because we were unable, due to the impossibility to see any scar indicating the tapering of the muscle, to take the tapering into account. In these two slices the erroneous result of the Persons method may therefore be caused by our inability to apply the method on them. Other reconstruction methods for the $\mathrm{m}$. caudofemoralis longus that assume the total muscle volume of the tail does not significantly exceed the tips of the transverse processes, neural arches and haemapophyses (e.g. Madsen, 1976; Carpenter et al., 2005; Arbour, 2009) would lead to even larger errors (Persons, 2009; Mallison, 2011).

\section{Discussion}

\section{Range of motion}

The supposed correlation of highly angled zygapophyses ( $\sim 40^{\circ}$ to near-vertical) and laterally limited joint flexibility (e.g. Cooper, 1981; Sereno, 1987; Barrett \& Upchurch, 2007), Hypothesis 1, could not be confirmed in our ex vivo experiments on Osteolaemus, nor by physical manipulation of skeletonized tails of Alligator mississippiensis, Crocodylus niloticus and C. intermedius. Photographs, photogrammetric 3D models and videos of living extant crocodilians also show that crocodilian tails are highly flexible laterally, despite highly angled zygapophyses, confirming that the Osteolaemus sampled in this study was not aberrant. Additionally, the per-joint lateral mobility does not correlate with zygapophyseal articulation surface angles (Error! Reference source not found.). It is well established that transversely (in anterior/posterior view) oriented zygapophyseal joints allow axial rotation, whereas radially aligned ones block it, as is the case in human thoracic and lumbar vertebrae. The former have "outturned" transversely aligned joints that allow axial rotation, the latter "inturned" radially aligned ones that block rotation (e.g. Milne, 1991). However, physically, it does not matter if the angle between the vertical and the joint surfaces is $0^{\circ}, 20^{\circ}$ or even $70^{\circ}$, as axial rotation is blocked by any alignment that differs strongly from a transverse orientation.

We only found a slightly lower degree of lateral mobility in our ex vivo experiment on Osteolaemus tetraspis as had previously been documented (Frey, 1982a). We also found this high lateral mobility Peer) PrePrints | https://dx.doi.org/10.7287/peerj.preprints.1339v1 | CC-BY 4.0 Open Access | rec: 2 Sep 2015, publ: 2 Sep 2015 
was confirmed by our own observations on living crocodylians, as well as film material of many different taxa including alligatorids. Additionally, manual manipulation of skeletonized material matched the mobility observed in living animals and the carcass. Therefore, the radially to vertically oriented zygapophyseal surfaces do not block lateral motion. Similarly, a number of fossil archosaur skeletons found with their tails strongly flexed to one side, both dinosaurs ( e.g. the troodontid theropod Sinornitholestes (Russell \& Dong, 1993), the psittacosaurid ornithischian Psittacosaurus (Ford \& Martin, 2010) and crocodylians (e.g. the famous Steneosaurus bollensis specimen from Ohmden in the IFGT (Westphal, 1962)). In some cases the tails were found articulated and circling around the animal, reminiscent of a curled-up sleeping cat (e.g. the troodontid theropod Mei long IVPP V12733, Xu \& Norell (2004)). These finds and observation of extant crocodiles and alligators should have sufficed to show that steeply angled zygapophyseal surfaces alone do not greatly hinder lateral motion.

The discrepancy in surface orientation between pre- and postzygapophyses in the distal tail in extant crocodylians (Table 3, PLEASE SEE SEPARATE FILE FOR Figure 2) coincides with the increase in long axis rotation/torsion described by Frey (1982a) in Alligator mississippiensis and evident in all living crocodilians we inspected. It also correlates with a change in shape of the articulation surfaces, which change from flat to slightly concave surfaces to a convex knob (postzygapophyses) and a noticeably concave depression. The articulation also shifts position to just above the centrum, although the anterior tips of the prezygapophyses move increasingly anterior and dorsal of the centrum. Together, these changes appear to remove the limiting effect that the radially oriented zygapophyses of more anterior caudal vertebrae have on intervertebral torsion. This demonstrates a more plausible function of the zygapophyses as a restriction to unwanted torsion rather than as a restriction to lateral flexibility, which has already been demonstrated for the neck of sauropods (Schwarz-Wings et al., 2010).

Additionally, the changes occur just posterior to the tapering of the M. caudofemoralis longus, which is the only non-segmented muscle in this region of the tail, and roughly coincides with the shape changed in the tips of the haemapophyses from simple to triangular that we observed in Crocodylus porosus. The terminal end of $\mathrm{m}$. caudofemoralis longus of extant crocodylians is dorsally met by a similar reduction of $\mathrm{m}$. spinalis of the $\mathrm{m}$. transversospinalis system. This indicates a functional correlation between epaxial musculature of the tail and $\mathrm{m}$. caudofemoralis longus - the former is needed to stabilize the tail during contraction of $\mathrm{m}$. caudofemoralis longus for femoral retraction, and can be reduced together with $\mathrm{m}$. caudofemoralis longus.

In this context it is also important to mention a study by Kuznetsov and Tereschenko (2010), who investigated the range of motion of the ceratopsian dinosaur Protoceratops andrewsi in comparison to extant sheep and developed a mathematical method for predicting mobility in the dorsoventral and horizontal plane from a set of measurements on the vertebrae. However, they did not calibrate their method with in vivo or ex vivo whole body measurements, but only with dissected specimens subjected to loading experiments (Kuznetsov \& Tereschenko, 2010). Although such experiments are highly repeatable, they are questionable in their reliability as recent investigations have shown convincingly that soft tissues have a much higher influence on mobility of the vertebral column than osteology (e.g. Dzemski \& Christian, 2007). Also, without X-rays of fully deflected and intermediate poses, it is difficult to determine the best approximation of the joints, which in life need not necessarily be single-axis rotation joints. 
Our experiments are only an initial stage in the necessary thorough and detailed assessment of how crocodylians tails can move. Much more effort will be needed to detail the per-joint limits of motion exactly, including $\mathrm{CT}$ investigations of several individuals each of several taxa, ideally with sedated animals instead of carcasses, and supplemented by further dissections of this region, as well as in vivo experiments documenting natural and voluntary behavior.

\section{Musculature}

Sellers et al. (2012) proposed a convex hull mass estimation and center of mass determination method for entire animals, based on 3D scans of mounted skeletons. This method was later used to estimate the masses of body parts, by directly applying the correction factor for entire mammalian bodies to functional sections of a non-avian dinosaur (Sellers, Margetts \& Coria, 2013). Both Persons (2009) and Mallison's (2011) results and the results of this study show clearly that tail bone extent is not a useful proxy for tail mass, because the soft tissues extend far further beyond the bone in the tail than in the trunk and neck, calling into question the use of the convex hull method with a uniform correction factor.

Properly limiting the shape (volume and path) of m. caudofemoralis longus is important for biomechanical modelling, as it is the primary hind limb retractor in archosaurs (Gatesy, 1990). Therefore, any overestimate of the force it produces results in an overestimate of hip extension moments, and thus leads to overestimates of locomotor performance, whereas an underestimate of the muscle's size results in an underestimate of locomotor prowess. If the muscle's force is to be estimated from its cross section, the shape of the anterior portion, where the muscle is largest, is of special importance. Especially problematic in this regard is the fact that joint torques are calculated as the product of muscular forces and their moment arms, with the force calculated as the muscle's physiological cross section area (PCSA) multiplied by its specific tension. An error in the reconstructed muscle size affects two of these variables: the PCSA and the moment arm (Mallison, 2011). Because these two variables are multiplied to calculate joint torque, the error is multiplied, too. If the PCSA as estimated is $75 \%$ of the correct value, the moment arm will also be underestimated e.g. $80 \%$ of the correct value. Assuming the other variables are estimated correctly, the calculate torque will be $80 \%$ of $75 \%$ of the correct value, i.e. only $60 \%$ of it. Conversely, seemingly minor overestimates of the two factors by $15 \%$ and $20 \%$ combine to overestimate joint torque by nearly $40 \%$ of the correct value.

In the past many reconstructions of tail musculature used the extent of the bone to limit the reconstructed soft tissues (e.g. Madsen, 1976; Paul, 1987; Myhrvold \& Currie, 1997; Carpenter et al., 2005; Arbour, 2009). Both Persons (2009) and Mallison (2011) argued for reconstructions with a higher muscle volume, based on comparisons to extant and functionally similar animals. Bates et al. (2009) created noticeably voluminous tails for their mass estimation models of dinosaurs. Here, measurements of the cross sections of m. caudofemoralis longus in Alligator mississippiensis compared to reconstructions based on the Persons method (Figure 4) show that the method can result in large errors that makes its results unreliable. Although the method delivers a good estimates of the total volume of the $\mathrm{m}$. caudofemoralis longus in non-archosaurian reptiles and in very small crocodilians (Persons, 2009), it fails to approximate the cross section areas and total volume well in adult crocodilians. The Persons method therefore should not be applied as published, and cannot be confirmed to function at least in the case of Alligator mississippiensis and Crocodylus porosus. As other crocodylians show similar ratios of soft tissue extents to bone tissue extents, the Persons method would also result in a massive underestimate of $\mathrm{m}$. caudofemoralis longus size in them. Peer) PrePrints | https://dx.doi.org/10.7287/peerj.preprints.1339v1 | CC-BY 4.0 Open Access | rec: 2 Sep 2015, publ: 2 Sep 2015 
The most noticeable problem is that the semicircle reconstructed using the Persons method does not correlate with the lateral extent of the transverse processes, especially at the tail base. As Persons (2009) detailed, the extent of the transverse processes is often a poor indicator for the lateral extent of $\mathrm{m}$. caudofemoralis longus. However, at the tail base $\mathrm{m}$. caudofemoralis longus is contained and firmly wrapped by $\mathrm{m}$. transversus perinei in crocodylians, which reaches laterally at least the tips of the transverse processes. Here, where $\mathrm{m}$. caudofemoralis longus is most massive and an error in reconstructing its cross section has the largest influence on any force estimate, reconstructing a lateral extent to the tips or to even less than the tips of the transverse processes therefore means basing the model on a rare potential exception to the rule, rather than the norm.

The basis of the Persons method for reconstructing the $\mathrm{m}$. caudofemoralis longus is a single osteological proxy for the reconstruction of the cross section at any given point, namely the dorsoventral distance between the base of the transverse process and the tip of the haemapophysis. It is therefore highly sensitive to any variation in the angle between the shaft of the haemapophysis and the long axis of the vertebra. Although this problem mostly affects extinct taxa, in which the angle must be reconstructed based on the small and often difficult to interpret articular facets between vertebrae and haemapophyses and thus is likely to vary between reconstructions, it could also be the reason for the large error we determined in the Persons method. Also, the CT scans of Crocodylus porosus we used were created with the animal's trunk and anterior tail placed venter down on the tray. As the carcass had been skinned, and thus an important component for its internal stability removed, it is possible that gravity compressed the body dorsoventrally, causing a shallower position of the haemapophyses and pressing the $m$. caudofemoralis longus laterally. In this case, we would have underestimated the cross section as determined via the Persons method, and the apparent lateral extent of the $\mathrm{m}$. caudofemoralis longus would be partly artificial. However, we find practically the same error for the Persons method on the physical tomographies of Alligator mississippiensis, which were photographed while resting on their anterior and posterior faces, with no dorsoventral compression occurring. Additionally, visual inspection of the skeleton of Crocodylus porosus extracted from the CT scans show the haemapophyses inclined roughly $40^{\circ}$ to $45^{\circ}$ from vertical, which is not an unusually shallow position (with the exception of the first haemapophysis, which is inclined by $23^{\circ}$, again a normal angle). Additionally, the posterior half of the tail had been cut off and placed alongside the trunk and anterior tail in the scan, but rotated so that is was resting on its lateral surface. In this section, the angles between haemapophyses and vertebral centra are highly similar to those in the anterior tail section, indicating that no significant compression has altered the anterior tail. Therefore, the error we determined for the Persons method is likely not caused by the skinning of the animal or the method of data capture.

For the other muscles of the tail, rules for reconstruction must remain even more vague than for the $\mathrm{m}$. caudofemoralis longus. In the case of $\mathrm{m}$. caudofemoralis brevis, the observed variability in origin and the absence of a feature unambiguously associated with this muscle (brevis fossa) in extant crocodylians demonstrates that using the crocodylian $\mathrm{m}$. caudofemoralis brevis for reconstructing the dinosaur $\mathrm{m}$. caudofemoralis brevis is likely not a useful approach, as the degree of uncertainty is much too high.

Biomechanically, due to the constraining effect of $m$. transversus perinei, which directly relates to the path of the tendon of $\mathrm{m}$. caudofemoralis longus, a larger cross section area for $\mathrm{m}$. caudofemoralis longus in the post-basal part of the tail would not result in a larger moment arm around the hip joint, so the error of a joint torque estimate would be proportional to the error in the PeerJ PrePrints | https://dx.doi.org/10.7287/peeri.preprints.1339v1 | CC-BY 4.0 Open Access | rec: 2 Sep 2015, publ: 2 Sep 2015 
muscle cross section only, and not a combined effect of errors relating to the cross section and moment arm. Only the moment arms versus the intra-tail joints are directly affected by changes in the cross section of $\mathrm{m}$. caudofemoralis. We conclude that a proper reconstruction of $\mathrm{m}$. transversus perinei is more important for an accurate estimate of hip joint moments than an exact determination of the taper point of $\mathrm{m}$. caudofemoralis longus.

The lack of attention given to $\mathrm{m}$. transversus perinei in the scientific literature is surprising given its potential ramifications for biomechanical modelling studies. Its curving path probably leads to a reduction of the moment arm of $\mathrm{m}$. caudofemoralis longus for extending the hip joint, and slightly increases the total length of the muscle. We hypothesize that the muscular sling formed by $\mathrm{m}$. transversus perinei may act to slightly alter the path and force vector of $\mathrm{m}$. caudofemoralis during hind limb motion, with the relative contraction of $\mathrm{m}$. transversus perinei presumably producing a range of path and force vector constraints. Further research is required to quantify this effect and determine how it influences the function of $\mathrm{m}$. caudofemoralis, if at all. In particular, does $\mathrm{m}$. transversus perinei enable $\mathrm{m}$. caudofemoralis to operate at the maximum force producing length for a wider range of hip flexion angles, which presumably helps to generate a range of powerful leg movements of benefit to locomotory prowess.

In sum, it becomes clear that the tails of extant crocodylians have not been studied in sufficient detail to maximize their utility as proxies for the tails of extinct archosaurs. Future research should focus on variations in the muscular anatomy within and across taxa, as there currently is little published detail concerning the exact origins, paths, insertions and fascial separation of tail muscles. Before data of extant crocodylians are used for quantitative data, there needs to be an improvement of the qualitative data as a basis. And although every scientist certainly aspires as much precision as possible in his reconstructions, it should be allowed for a certain range of variability with the figures. This means that it is often better to keep to a rougher estimate and calculate a wider range of possibility, than to predict such reconstruction with too much precision that does not correlate with the data. Finally, although both dinosaurs and crocodylians are archosaurs, is should be kept in mind that crocodylians with their semiaquatic lifestyle and behavioral differences might not necessarily be good proxies for dinosaurs.

\section{Conclusions}

- Reconstructing the CFL of an extinct archosaurs alone using the Persons method, without the context of the remaining tail muscles, e.g. for analyses of limb motion, usually reduces the available data for its length and cross section area to two osteological correlates, the vertical distance between transverse process and tip of the haemapophysis for the dorsoventral extent and the presence of transverse processes as a correlate for posterior extent. The position of the tips of the haemapophyses is directly dependent on the angle at which the haemapophyses are placed. We therefore recommend against such reconstructions.

Additionally, the Persons method uses a semicircle based on the osteological correlates to estimate the lateral extent of the muscle. For most of the length of the muscle the cross section is massively underestimated. We attempted to find simple geometric rules

PeerJ PrePrints | https://dx.doi.org/10.7287/peerj.preprints.1339v1 | CC-BY 4.0 Open Access | rec: 2 Sep 2015, publ: 2 Sep 2015 
for recreating a better approximation, but found that the CFL's cross section geometry changes too much along the length of the muscle for a simple rule to match it.

- If an intermuscular scar is visible on the haemapophysis the posterior extent is better constraint. Therefore, an effort should always be made to check for the presence of such a scar, as has been suggested by Persons (2009).

- Reconstructing the whole tail musculature in 3D takes the inter-muscle relations into account, but it is difficult to estimate at what angle the fibers of the $\mathrm{m}$. ischio-iliocaudalis inserted into the transverse processes in a fossil. Therefore, it is still difficult to determine the lateral extent of the entire tail and the individual muscle groups in it.

- When reconstructing the life appearance of an extinct non-avian archosaurs practically any shape can be chosen for the tail as long as the soft tissues extend far beyond the bones and the cross section is somewhat roundish, oval or rounded-rectangular. Any volume that is "too much" muscle can be argued to be caused by fat deposits.

- In order to create a best-guess approximation we recommend using cross section data from extant crocodilians and matching it to the respective position, proportional to total tail length. Then, the cross section data should be scaled to match the transverse process width and the dorsoventral extent of the haemapophyses and neural arches of the fossil taxon. If necessary, two separate sets of cross section data should be used, one to match the haemapophyses and one to match the neural arches. This way, the extinct species is reconstructed with a crocodilian-type tail, the best possible starting point. Any osteological differences, like a wider pelvis, can then be taken into account, and the muscles adapted accordingly. To encourage the adoption of this refined reconstruction method we have provide cross section data for Alligator mississippiensis.

- When modelling non-avian dinosaur tails for biomechanical analyses we need to run sensitivity analyses with greater ranges for especially transverse tail extent and thus $m$. caudofemoralis cross section than is commonly done.

- Thorough further study of inter- and intraspecific variation of crocodilian tail muscles is needed to create a better data base for reconstructing non-avian dinosaur tails.

\section{Financial Statement}

This study was supported by the University Research Committee of the University of Hong Kong through the Seed Funding Programme for Basic Research (201304159004) and Conference Support for Teaching Staff (201407170124), as well as the University's Faculty of Science. HM received funding from the Deutsche Forschungsgemeinschaft DFG under grant SCHW1453/2-1.

\section{Acknowledgements}

We would like to take the opportunity to thank A. Klinkhammer and S. Wroe (UNE), R. Wilhite and D. Hillmann (AUCVM) and J.R. Hutchinson (RVC) for contributing invaluable data as well as specimen and facility access. We consider ourselves very lucky to have such generous and supportive colleagues. We also thank A. Watanabe (AMNH) for advice on the manuscript. HM received funding from the German Science Foundation under grant DSW 1452/3-1. 


\section{References}

Allen VR. 2010. The evolution of avian hindlimb conformation and locomotor function. London, U.K.:

The Royal Veterinary College, University of London.

Allen V, Molnar J, Parker W, Pollard A, Nolan G, Hutchinson JR. 2014. Comparative architectural properties of limb muscles in Crocodylidae and Alligatoridae and their relevance to divergent use of asymmetrical gaits in extant Crocodylia. Journal of Anatomy 255:569-582.

Allen VR, Paxton H, Hutchinson JR. 2009. Variation of center of mass estimates for extant sauropsids and its importance for reconstructing inertial properties of extinct archosaurs. Anatomical Record 292:1442-1461.

Arbour VM. 2009. Estimating impact forces of tail club strikes by ankylosaurid dinosaurs. PLoS ONE 4:e6738.

Barrett PM, Upchurch P. 2007. The evolution of feeding mechanisms in early sauropodomorphdinosaurs. In: Barrett PM, Batten DJ eds. Evolution and Palaeobiology of Early Sauropodomorph Dinosaurs (Special Papers in Palaeontology 77). Oxford: Blackwell Scientific Publications, 91-112.

Bates KT, Manning PL, Hodgetts D, Sellers W. 2009. Estimating the mass properties of dinosaurs using laser imaging and 3D computer modeling. PLoS ONe 4(2):e4532.

Bates KT, Maidment SCR, Allen VR, Barrett PM. 2012. Computational modelling of locomotor muscle moment arms in the basal dinosaur Lesothosaurus diagnosticus: assessing convergence between birds and basal ornithischians. Journal of Anatomy 220:212-132.

Buttmann H. 1826. De musculis crocodili. Inaugural Thesis Thesis. Halle, GER: Universität Halle. Carpenter K, Sanders F, McWhinney LA, Wood L. 2005. Evidence for predator-prey relationships. Examples for Allosaurus and Stegosaurus. In: Carpenter K ed. The Carnivorous Dinosaurs. Bloomington: Indiana University Press, 325-350.

Carrano MT, Hutchinson JR. 2003. The pelvic and hind limb musculature of Tyrannosaurus rex (Dinosauria: Theropoda). Journal of Morphology 253:207-228. 
Cobley MJ, Rayfield EJ, Barrett PM. 2013. Inter-vertebral flexibility of the ostrich neck: Implications for estimating sauropod neck flexibility. PLOS ONE 8:e72187.

Cong L, Hou L, Wu X, Hou J. 1998. The gross anatomy of Alligator sinensis Fauvel. Beijing: Forestry Publishing House.

Cooper MR. 1981. The prosauropod dinosaur Massospondylus carinatus Owen from Zimbabwe: its biology, mode of life and phylogenetic significance. Occasional Papers, National Museums and Monuments of Rhodesia, Series B, Natural Sciences 6:689-840.

Cuvier G. 1835. Lecons d'anatomie comparée. Paris: Crochard.

Davenport J, Sayer MDJ. 1989. Observations on the aquatic locomotion of young salt-water crocodiles (Crocodylus porosus Schneider). Herpetological Journal.

Dilkes DW. 2000. Appendicular myology of the hadrosaurian dinosaur Maiasaura peeblesorum from the Late Cretaceous (Campanian) of Montana. Transactions of the Royal Society of Edinburgh: Earth Sciences 90:87-125.

Dzemski G, Christian A. 2007. Flexibility along the neck of the ostrich (Struthio camelus) and consequences for the reconstruction of dinosaurs with extreme neck length. Journal of Morphology 268:701-714.

Faux CM, Padian K. 2007. The opisthotonic posture of vertebrate skeletons: postmortem contraction or death throes? Paleobiology 33:201-226.

Fechner R. 2009. Morphofunctional Evolution of the Pelvic Girdle and Hindlimb of Dinosauromorpha on the Lineage to Sauropoda. Doctoral Thesis Thesis. Munich: Ludwigs Maximilians Universität.

Fish FE. 1984. Kinematics of undulatory swimming in the American alligator. Copeia 1984:839-843.

Fish FE, Bostic SA, Nicastro AJ, Beneski JT. 2007. Death roll of the alligator: mechanics of twist feeding in water. Journal of Experimental Biology 210:2811-2818.

Ford TL, Martin LD. 2010. A semi-aquatic life habit for Psittacosaurus. In: Ryan MJ, Chinnery-Allgeier BJ, Eberth DA eds. New Perspectives on Horned Dinosaurs: The Royal Tyrrell Museum Ceratopsian Symposium. Bloomington and Indianapolis: Indiana University Press, 328-339. Peerj PrePrints | https://dx.doi.org/10.7287/peerj.preprints.1339v1 | CC-BY 4.0 Open Access | rec: 2 Sep 2015, publ: 2 Sep 2015 
Frey E. 1982a. Der Bau des Bewegungsapparates der Krokodile und seine Funktion bei der aquatischen Fortbewegung. Diploma Thesis Thesis. Tübingen: Tübingen.

Frey E. 1982b. Ecology, locomotion, and tail muscle anatomy of crocodiles. Neues Jahrbuch fur Geologie und Paläontologie - Abhandlungen 164:194-199.

Frey E. 1988. Anatomie des Körperstammes von Alligator mississippiensis Daudin (Anatomy of the body stem of Alligator mississippiensis Daudin). Stuttgarter Beiträge zur Naturkunde, Series A (Biologie) 424:1-106.

Frey E, Riess J, Tarsitano SF. 1989. The axial tail musculature of recent crocodiles and its phyletic implications. American Zoologist 29:857-862.

Frey E, Salisbury SW. 2001. Crocodilian biology and evolution. In: Grigg GC, Seebacher F, Franklink CE eds. The kinematics of aquatic locomotion in Osteolaemus tetraspis Cope. Chipping Norton, NSW, AUS: Surrey Beatty \& Sons, 165-179.

Gadow H. 1882. Beiträge zur Myologie der hinteren Extremität der Reptilien. Morphologisches Jahrbuch 7:329-466.

Gatesy SM. 1990. Caudofemoral musculature and the evolution of theropod locomotion. Paleobiology 16:170-186.

Gorski C. 1852. Über das Becken der Saurier: Eine vergleichend-anatomische Abhandlung zur Erlangung der Magister-Würde. Dorpat: Laakmann.

Hair P. 1868a. On the arrangement of the muscular fibers of the alligator. Journal of Anatomy 2:2641.

Hair P. 1868b. On the arrangement of the muscle fibres of the alligator. Journal of Anatomy and Physiology 2:26-41.

Haughton S. 1865. On the muscular anatomy of the leg of the Crocodile. Annals And Magazine of Natural History 16:326-331.

Hennig E. 1913. Über dorsale Wirbelsäulenkrümmung fossiler Vertebraten. Centralblatt für Mineralogie, Geologie und Paläontologie 1913:575-577. 
Hennig E. 1925. Kentrurosaurus aethiopicus Die Stegosaurier-Funde vom Tendaguru, DeutschOstafrika. Palaeontographica Supplement 7:101-254.

Hongo M, Gay RE, Hsu JT, Zhao KD, Ilharreborde B, Berglund L, An KN. 2008. Effect of multiple freeze-thaw cycles on intervertebral dynamic motion characteristics in the porcine lumbar spine. Journal of Biomechanics 41:916-920.

Huene F v. 1926. Vollständige Osteologie eines Plateosauriden aus dem schwäbischen Keuper. Geologische und Palaeontologische Abhandlungen, Neue Folge 15:139-179.

Hutchinson JR. 2001. The evolution of pelvic osteology and soft tissues on the line to extant birds (Neornithes). Zoological Journal of the Linnean Society 131:123-168.

Hutchinson JR. 2004a. Biomechanical modeling and sensitivity analysis of bipedal running ability. I. Extant taxa. Journal of Morphology 262:421-440.

Hutchinson JR. 2004b. Biomechanical modeling and sensitivity analysis of bipedal running ability. II. Extinct taxa. Journal of Morphology 262:441-461.

Hutchinson JR, Anderson FC, Blemker S, Delp SL. 2005. Analysis of hindlimb muscle moment arms in Tyrannosaurus rex using a three-dimensional musculoskeletal computer model: implications for stance, gait, and speed. Paleobiology 31:676-701.

Hutchinson JR, Gatesy SM. 2000. Adductors, abductors, and the evolution of archosaur locomotion. Paleobiology 26:734-751.

Ibiricu LM, Lamanna M, Lacovara K. 2014. The influence of caudofemoral musculature on the titanosaurian (Saurischia: Sauropoda) tail skeleton: morphological and phylogenetic implications. Historical Biology 26:454-471.

Kälin JA, Knüsel L. 1944. Über die Lokomotion der Crocodiliden. Revue suisse de Zoologie 51:389-393. Kuznetsov AN, Tereschenko VS. 2010. A method for estimation of lateral and vertical mobility of platycoelous vertebrae of tetrapods. Paleontological Journal 44:209-225.

Madsen JH. 1976. Allosaurus fragilis: A Revised Osteology. Salt Lake City: Utah Geological Survey. 
Maidment SCR, Bates KT, Falkingham PL, VanBuren C, Arbour VM, Barrett PM. 2013. Locomotion in ornithischian dinosaurs: an assessment using three-dimensional computational modeling. Biological Reviews.

Mallison H. 2010a. CAD assessment of the posture and range of motion of Kentrosaurus aethiopicus Hennig 1915. Swiss Journal of Geosciences 103:211-233.

Mallison H. 2010b. The digital Plateosaurus II: an assessment of the range of motion of the limbs and vertebral column and of previous reconstructions using a digital skeletal mount. Acta Palaeontologica Polonica 55:433-458.

Mallison H. 2011. Defense capabilities of Kentrosaurus aethiopicus Hennig, 1915. Palaeontologia Electronica 14:10A.

Manter JT. 1940. The mechanics of swimming in the alligator. Journal of Experimental Zoology 83:345-358.

Milne M. 1991. The role of zygapophysial joint orientation and uncinate processes in controlling motion in the cervical spine. Journal of Anatomy 178:189-201.

Myhrvold NP, Currie PJ. 1997. Supersonic sauropods? Tail dynamics in diplodocids. Paleobiology 23:393-403.

Norman DB. 1986. On the anatomy of Iguanodon atherfieldensis (Ornithischia: Ornithopoda). Bulletin de L'Institut Royal des Sciences Naturelles de Belgique, Sciences de la Terre 56:281-37.

Panjabi MM, Summers D, Videman T. 1985. Biomechanical time-tolerance of fresh cadaveric human spine specimens. Journal of Orthopaedic Research 3:292-300.

Paul GS. 1987. The science and art of restoring the life appearance of dinosaurs and their relatives. A rigorous how-to guide. In: Czerkas SJ, Olson EC eds. Dinosaurs Past and Present Volume II. Los Angeles: Natural History Museum of Los Angeles County Press, 5-49.

Penkalski P. 2001. Variation in specimens referred to Euoplocephalus tutus. In: Carpenter K ed. The Armored Dinosaurs. Bloomington, Indiana: Indiana University Press, 261-298. 
Persons W. 2009. Theropod tail muscle reconstruction and assessment of the locomotive contributions of the M. caudofemoralis. Journal of Vertebrate Paleontology Supplement to No.3:164A.

Persons W, Currie PJ. 2011. The tail of Tyrannosaurus: Reassessing the size and locomotive importance of the M. caudofemoralis in non-avian theropods. Anatomical Record 294:119131.

Persons W, Currie PJ, Norell MA. 2014. Oviraptorosaur tail forms and functions. Acta Palaeontologica Polonica 59:553-567.

Ringma JL, Salisbury SW. 2013. Aquatic Locomotor Kinematics of the Eastern Water Dragon (Intellagama lesueurii). Journal of Herpetology 48:240-248.

Romer AS. 1923a. Crocodilian pelvic muscles and their avian and reptilian homologues. Bulletin of the American Museum of Natural History New York 48:533-552.

Romer AS. 1923b. The pelvic musculature of saurischian dinosaurs. Bulletin of the American Museum of Natural History New York 48:605-617.

Romer AS. 1927. The pelvic musculature of ornithischian dinosaurs. Acta Zoologica 8:225-275.

Russell DA, Dong Z. 1993. A nearly complete skeleton of a new troodontid dinosaur from the Early Cretaceous of the Ordos Basin, Inner Mongolia, People's Republic of China. Canadian Journal of Earth Sciences 30:2163-2173.

Salisbury SW. 2001. A biomechanical transformation model for the evolution of the eusuchian-type bracing system.

Salisbury SW, Frey E. 2001. A biomechanical transformation model for the evolution of semispheroidal articulations between adjoining vertebral bodies in crocodilians. In: Grigg GC, Seebacher F, Franklink CE eds. Crocodilian biology and evolution. Chipping Norton, NSW, AUS: Surrey Beatty \& Sons, 121-148.

Schwarz D, Frey E, Meyer CA. 2007. Novel reconstruction of the orientation of the pectoral girdle in sauropods. Anatomical Record 290:32-47. 
Schwarz-Wings D, Meyer CA, Frey E, Manz-Steiner H-R, Schumacher R. 2010. Mechanical iplications of pneumatic neck vertebrae in sauropod dinosaurs. Proceedings of the Royal Society of London. Series B: Biological Sciences 277:11-17.

Schwarz D, Wings O, Meyer CA. 2007. Super sizing the giants: first cartilage preservation at a sauropod dinosaur limb joint. Journal of the Geological Society London 164:61-65.

Seebacher F, Elsworth P, Franklin C. 2003. Ontogenetic changes of swimming kinematics in a semiaquatic reptile (Crocodylus porosus). Australian Journal of Zoology 51:15-24.

Sellers WI, Hepworth-Bell J, Falkingham PL, Bates KT, Brassey CA, Edgerton VM, Manning PL. 2012. Minimum convex hull mass estimations of complete mounted. Biology Letters.

Sellers WI, Margetts L, Coria RA. 2013. March of the Titans: the locomotor capabilities of sauropod dinosaurs. PLOS ONE 8(10):e78733.

Sereno PC. 1987. The Ornithischian Dinosaur Psittacosaurus from the Lower Cretaceous of Asia and the Relationship of the Ceratopsia. Ph.D. Thesis Thesis. New York: Columbia University.

Stannius H. 1854. Handbuch der Anatomie der Wirbeltiere. Berlin: Veit.

Stevens KA, Parrish JM. 1999. Neck posture and feeding habits of two Jurassic sauropod dinosaurs. Science 284:798-800.

Stevens KA, Parrish JM. 2005a. Digital reconstructions of sauropod dinosaurs and implications for feeding. In: Curry-Rogers KA, Wilson JA eds. The sauropods: Evolution and Paleobiology. Berkeley: University of California Press, 178-200.

Stevens KA, Parrish JM. 2005b. Neck posture, dentition, and feeding strategies in Jurassic sauropod dinosaurs. In: Carpenter K, Tidwell V eds. Thunder Lizards: The Sauropodomorph Dinosaurs. Bloomington: Indiana University Press, 212-232.

Taylor MP, Wedel MJ, Naish D. 2009. Head and neck posture in sauropod dinosaurs inferred from extant animals. Acta Palaeontologica Polonica 54:213-220.

Tsuihiji T. 2005. Homologies of the transversospinalis muscles in the anterior presacral region of Sauria (crown Diapsida). Journal of Morphology 263:151-178. 
Westphal F. 1962. Die Krokodilier des Deutschen und Englischen Oberen Lias. Palaeontographica Abteilung A 118:23-118.

Wilhite DR. 2003. Digitizing large fossil skeletal elements for three-dimensional applications. Palaeontologia Electronica 5:http://palaeo-electronica.org/2002_2/scan/issue2_02.htm. Xu X, Norell MA. 2004. A new troodontid dinosaur from China with avian-like sleeping posture. Nature 431:838-841. 


\section{Figures}
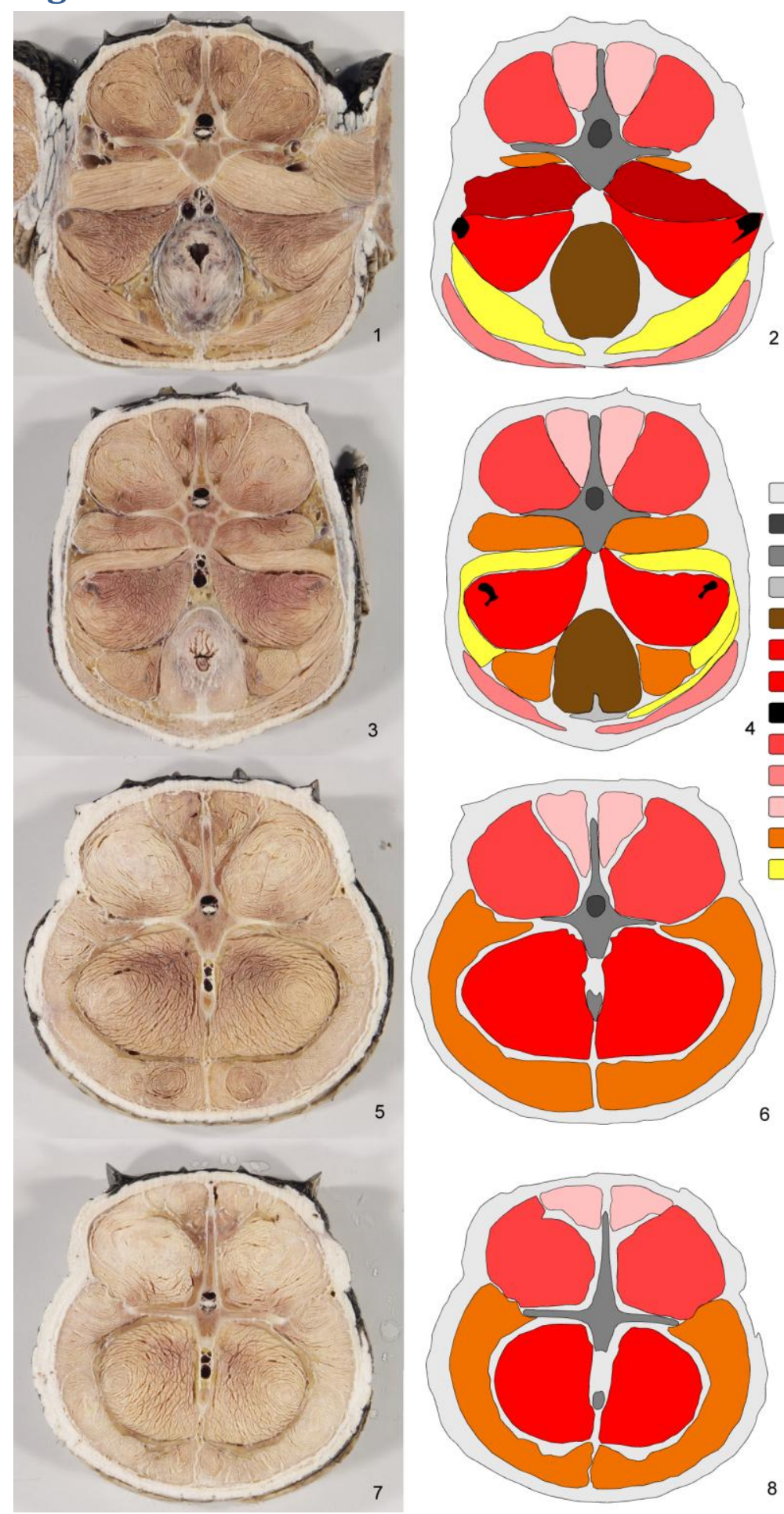

Body outline
Neural canal
Bone
Cartilago cloaca

Cloacal tissues

M. caudofemoralis brevis

M. caudofemoralis longus

- tendon

M. longissimus caudae
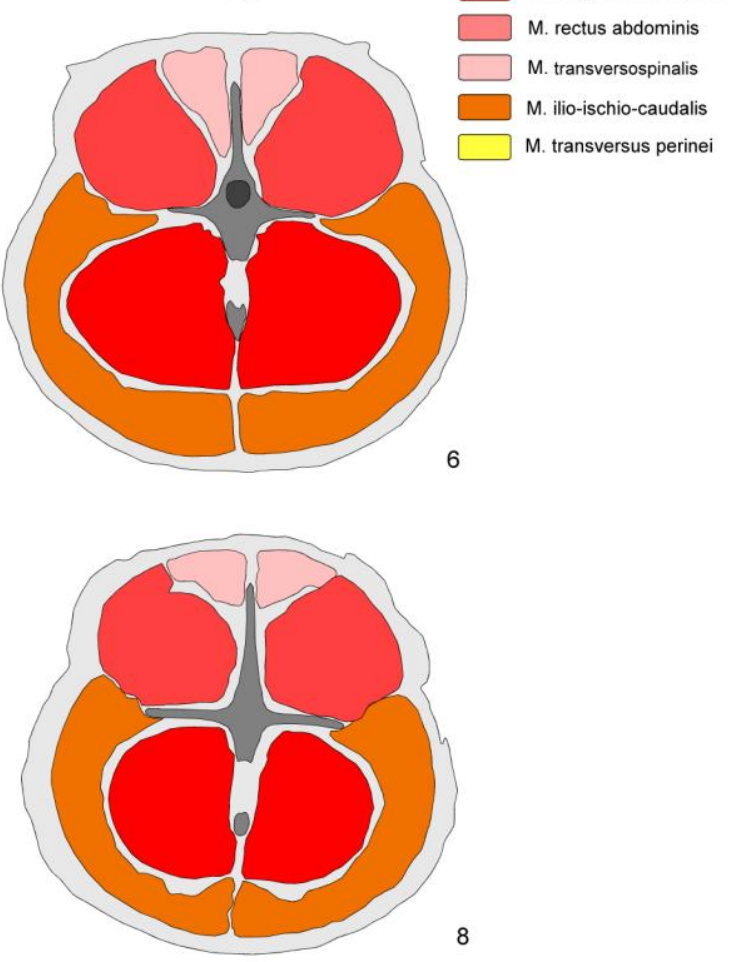

Figure 1. Physical tomography slices of the tail of Alligator mississippiensis. Left: photographs, right: interpretative drawings. 1 \& 2, slices just posterior to the pelvis showing the $\mathrm{m}$. caudofemoralis brevis, $3 \& 4$, at the level of the $\mathrm{m}$. transversus perinei, $5 \& 6$, just posterior to the $\mathrm{m}$. transversus perinei, and $7 \& 8$, from ca. two-thirds down the tail showing the dorsal offset of the $\mathrm{m}$. longissimus caudae / $\mathrm{m}$. transversospinalis contact on the neural arch. 
PLEASE SEE SEPARATE FILE FOR Figure 2. ex vivo mobility of the tail of Osteolaemus tetraspis (blue marks and lines) compared to inclination of zygapophyseal articulation surfaces in Alligator mississippiensis (HU Zool.Coll. 1914 Nr. 81, pink), Crocodylus porosus (IPFUB OS 13, green) and Crocodylus niloticus (ZMB 82861, red). Note that in C. niloticus the values from ca. caudal vertebra 12 on are unreliable, because the zygapophyseal surfaces face almost posteriorly, and are difficult to measure in axial photographs.

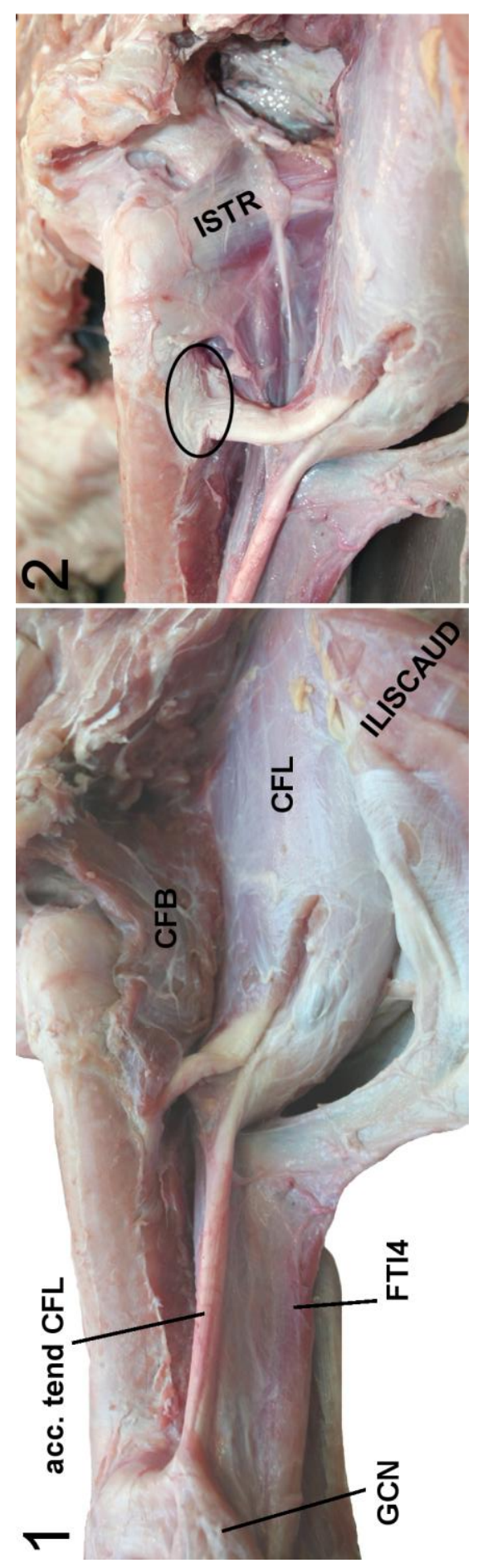

Figure 3. Images from dissection of Crocodylus niloticus ZMB 82861 (by DS). 1 ventral view of the left femur, with superifical muscles removed. 2. As 1, but with CFB removed to reveal ISTR and origin of CFB (circled). Abbreviations: acc. 
tend $\mathrm{CFL}=$ accessory tendon of $\mathrm{CFL}, \mathrm{CFB}=\mathrm{m}$. caudofemoralis brevis, $\mathrm{CFL}=\mathrm{m}$. caudofemoralis longus, $\mathrm{FTI} 4=\mathrm{m}$. femorotibialis 4, ILISCAUD = m. ilio-ischio-caudalis, ISTR $=m$. ischiotrochantericus. 


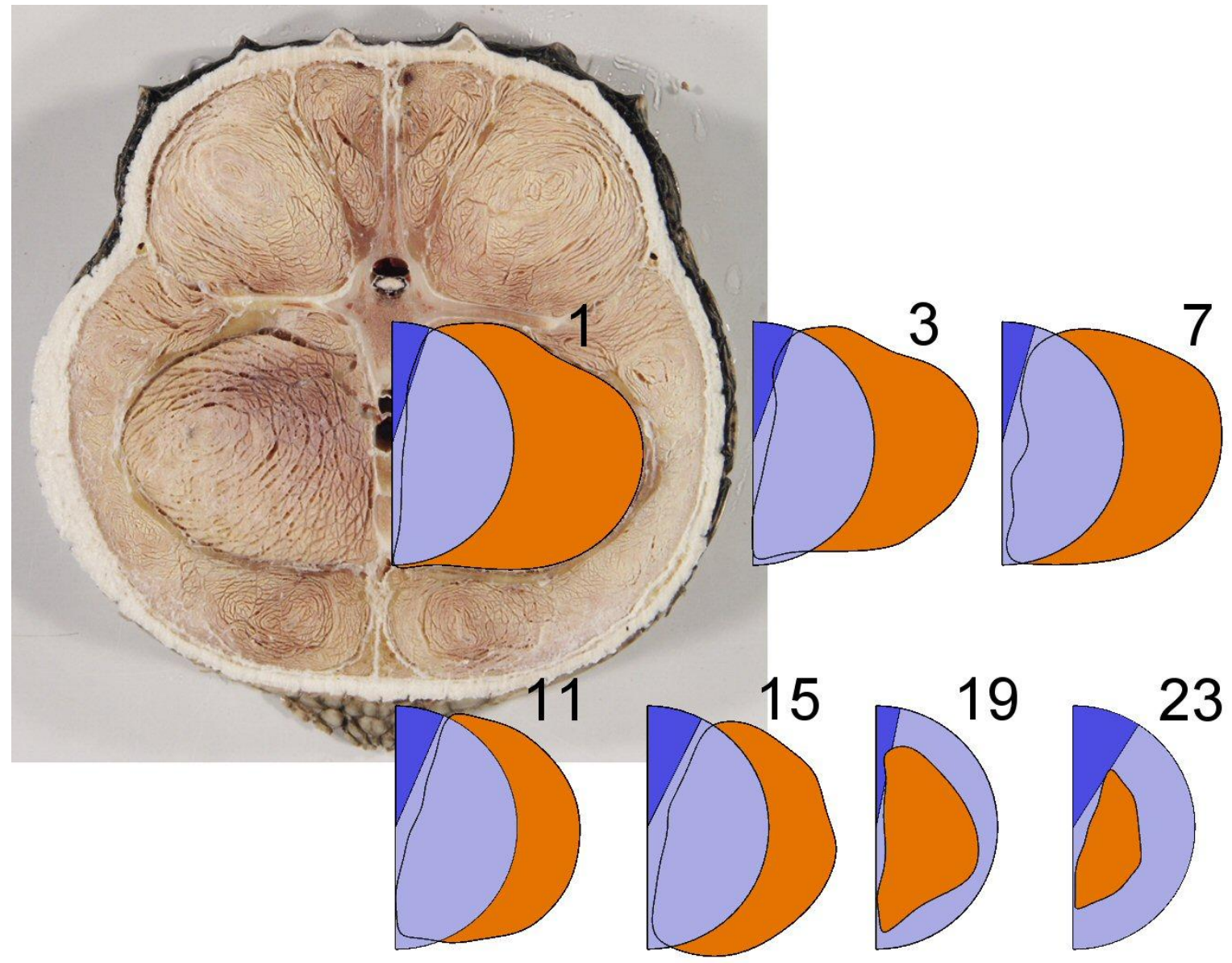

Figure 4. Difference in cross section are of the $\mathrm{m}$. caudofemoralis longus in Alligator mississippiensis between the Persons' (2009) method (light blue - arc version, dark blue - semicircle version) and a tracing of the muscle on section photographs. Numbers relate to relative position of slice, with 1 being the first post-cloacal slice. Distal tapering of the $\mathrm{m}$. caudofemoralis longus (i.e. the muscle not attaching to the full lateral surface of the haemapophyses) begins between slices 15 and 19. See text for further details. 


\section{Tables}

Table 1: Underestimation (in \%) of the cross section of the M. caudofemoralis longus of Alligator mississippiensis from a representative sample of physical tomographies using the Persons (2009) method compared to the actual measurements. Results of the Persons method in slices $\mathbf{2 5}$ and 29 may be erroneous due to us misreading equivocal osteological correlates.

\begin{tabular}{|c|c|c|c|c|}
\hline $\begin{array}{l}\text { Slice no. from } \\
\text { caudal } 1\end{array}$ & $\begin{array}{l}\text { Slice number } \\
\text { from cloaca }\end{array}$ & Slice name & $\begin{array}{r}\text { Underestimatation a } \\
\text { actual meas }\end{array}$ & $\begin{array}{l}\text { s a percentage of the } \\
\text { urement (\%) }\end{array}$ \\
\hline & & & $\%$ of 'arc' method & $\%$ of 'semicircle' \\
\hline 7 & 1 & РICT0390 & 57 & 52 \\
\hline 9 & 3 & РІСТ0392 & 47 & 41 \\
\hline 13 & 7 & РICT0396 & 48 & 43 \\
\hline 17 & 11 & РICT0400 & 36 & 26 \\
\hline 21 & 15 & РІСТ0404 & 38 & 27 \\
\hline 25 & 19 & РICT0408 & -75 & -87 \\
\hline 29 & 23 & РІСТ0412 & -226 & -298 \\
\hline
\end{tabular}


Table 2: Joint angles of maximally deflected tail of Osteolaemus tetraspis, measured on 3D files extracted from CT scans. For lateral flexion only the anterior half of the tail was deflected.

\begin{tabular}{|c|c|c|c|c|c|}
\hline Joint & Anterior & Posterior & & Mobility & \\
\hline & & & Lateral & Dorsal & Ventral \\
\hline 0 & last sacral & caudal 1 & 5.2 & 5.6 & 2.2 \\
\hline 1 & caudal 1 & caudal 2 & 8.1 & 6.5 & 1.5 \\
\hline 2 & caudal 2 & caudal 3 & 13.4 & 9.1 & 1.7 \\
\hline 3 & caudal 3 & caudal 4 & 14.4 & 6.8 & 2.4 \\
\hline 4 & caudal 4 & caudal 5 & 15.6 & 6.5 & 4.0 \\
\hline 5 & caudal 5 & caudal 6 & 15.8 & 5.9 & 5.2 \\
\hline 6 & caudal 6 & caudal 7 & 17.6 & 6.8 & 5.0 \\
\hline 7 & caudal 7 & caudal 8 & 18.4 & 7.1 & 7.2 \\
\hline 8 & caudal 8 & caudal 9 & 18.9 & 5.2 & 8.8 \\
\hline 9 & caudal 9 & caudal 10 & 17.4 & 3.7 & 10.6 \\
\hline 10 & caudal 10 & caudal 11 & 17.2 & 2.0 & 10.3 \\
\hline 11 & caudal 11 & caudal 12 & 15.0 & 2.4 & 10.8 \\
\hline 12 & caudal 12 & caudal 13 & 15.5 & 3.2 & 9.5 \\
\hline 13 & caudal 13 & caudal 14 & & 5.5 & 10.5 \\
\hline 14 & caudal 14 & caudal 15 & & 6.5 & 7.6 \\
\hline 15 & caudal 15 & caudal 16 & & 7.8 & 6.5 \\
\hline 16 & caudal 16 & caudal 17 & & 8.2 & 4.3 \\
\hline 17 & caudal 17 & caudal 18 & & 8.5 & 5.8 \\
\hline 18 & caudal 18 & caudal 19 & & 7.8 & 6.4 \\
\hline 19 & caudal 19 & caudal 20 & & 4.6 & 4.7 \\
\hline 20 & caudal 20 & caudal 21 & & 3.0 & 4.0 \\
\hline 21 & caudal 21 & caudal 22 & & 2.3 & 4.8 \\
\hline 22 & caudal 22 & caudal 23 & & & 6.0 \\
\hline 23 & caudal 23 & caudal 24 & & & 5.5 \\
\hline 24 & caudal 24 & caudal 25 & & & 5.0 \\
\hline
\end{tabular}


Table 3: Inclinations of the zygapophyseal articulation surfaces from the vertical in Crocodylus porosus (IPFUB OS 13), Alligator mississippiensis (Zool.Coll. 1914 Nr. 81) and C. niloticus (ZMB 82861), measured on photographs taken in axial view.

Inclination from the vertical $\left({ }^{\circ}\right)$

\begin{tabular}{|c|c|c|c|c|c|}
\hline \multirow[b]{2}{*}{$\begin{array}{l}\text { Joint } \\
\text { No. }\end{array}$} & IPFUB OS 13 & \multicolumn{2}{|c|}{ Zool.Coll. 1914 Nr. 81} & \multicolumn{2}{|c|}{ ZMB 82861} \\
\hline & $\begin{array}{l}\text { Pre- } \\
\text { zygapophyses }\end{array}$ & $\begin{array}{l}\text { Pre- } \\
\text { zygapophyses }\end{array}$ & $\begin{array}{l}\text { Post- } \\
\text { zygapophyses }\end{array}$ & $\begin{array}{l}\text { Pre- } \\
\text { zygapophyses }\end{array}$ & $\begin{array}{l}\text { Post- } \\
\text { zygapophyses }\end{array}$ \\
\hline 1 & 45.0 & & & 53.0 & 49.1 \\
\hline 2 & 50.0 & 52.4 & 54.6 & 53.3 & 41.8 \\
\hline 3 & 46.6 & 54.5 & 54.6 & 43.1 & 43.2 \\
\hline 4 & 48.8 & 55.2 & 53.8 & 47.1 & 37.8 \\
\hline 5 & 48.1 & 52.1 & 50.8 & 44.6 & 44.3 \\
\hline 6 & 40.1 & 50.0 & 48.6 & 47.2 & 39.1 \\
\hline 7 & 38.4 & 47.1 & 40.8 & 44.5 & 35.7 \\
\hline 8 & 35.6 & 40.8 & 43.1 & 39.6 & 26.6 \\
\hline 9 & 35.9 & 43.4 & 41.8 & 31.4 & 26.0 \\
\hline 10 & 28.4 & 42.1 & 34.2 & 26.2 & 25.7 \\
\hline 11 & 30.2 & 35.9 & 36.2 & 26.5 & 23.2 \\
\hline 12 & 29.4 & 37.8 & 36.7 & 31.9 & 30.2 \\
\hline 13 & 30.7 & 35.2 & 28.1 & 32.5 & 23.7 \\
\hline 14 & 26.4 & 29.1 & 24.0 & 30.5 & 35.0 \\
\hline 15 & 22.6 & 26.0 & 24.1 & & 38.3 \\
\hline 16 & & 25.6 & 19.9 & 38.4 & 33.9 \\
\hline 17 & & 20.2 & 18.3 & 35.9 & 26.5 \\
\hline 18 & & 13.6 & 18.0 & 30.1 & 34.6 \\
\hline 19 & & 15.8 & 16.4 & 28.5 & 30.5 \\
\hline 20 & & 13.1 & 16.5 & 23.5 & 26.2 \\
\hline 21 & & 18.4 & 16.4 & 24.5 & 26.4 \\
\hline 22 & & 12.1 & 13.0 & & \\
\hline 23 & & 12.5 & 11.2 & & \\
\hline 24 & & 22.0 & 9.1 & & \\
\hline 25 & & 27.4 & 9.0 & & \\
\hline 26 & & 24.8 & 7.7 & & \\
\hline 27 & & 25.0 & 8.1 & & \\
\hline 28 & & 23.0 & 9.3 & & \\
\hline 29 & & 22.4 & 9.1 & & \\
\hline 30 & & 18.2 & 10.0 & & \\
\hline 31 & & 11.8 & 10.6 & & \\
\hline
\end{tabular}




\section{1}

Figure 2

ex vivo mobility of the tail of Osteolaemus tetraspis (blue marks and lines) compared to inclination of zygapophyseal articulation surfaces in Alligator mississippiensis (HU Zool.Coll. 1914 Nr. 81, pink), Crocodylus porosus (IPFUB OS 13, green) and Crocodylus niloticus (ZMB 82861 , red). Note that in C. niloticus the values from ca. caudal vertebra 12 on are unreliable, because the zygapophyseal surfaces face almost posteriorly, and are difficult to measure in axial photographs.

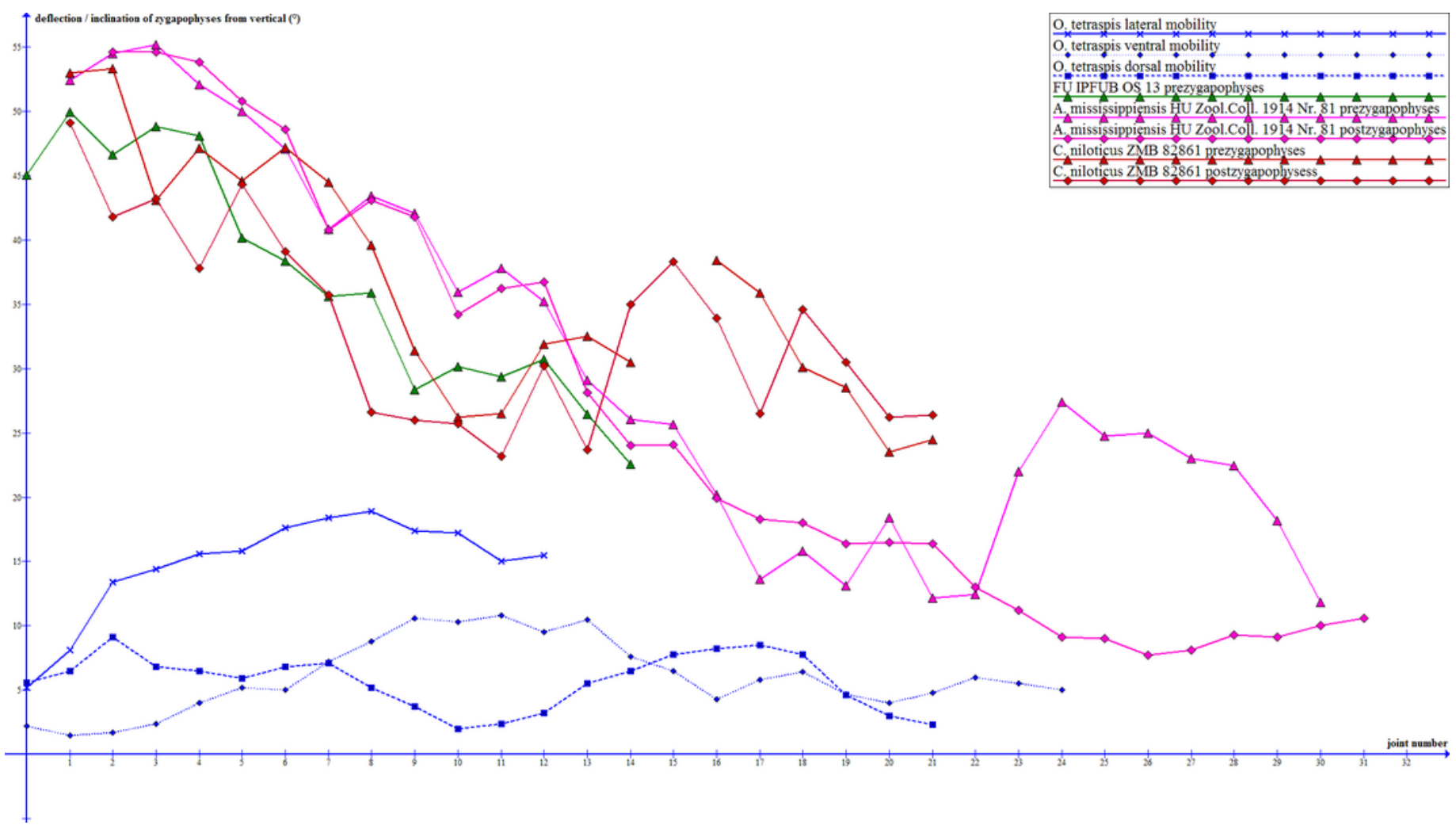

